\title{
Liquidity and prices: A cluster analysis of the German residential real estate market
}

\author{
Marcelo Cajias ${ }^{1}$. Philipp Freudenreich ${ }^{2}$ (D) Anna Freudenreich ${ }^{2}$. \\ Wolfgang Schäfers ${ }^{2}$
}

Published online: 16 August 2020

() The Author(s) 2020

\begin{abstract}
This paper analyses the highly under-researched German residential real estate market. Quality- and spatial-adjusted price and liquidity indices are calculated separately for the investment and rental market on a regional basis. Applying the "Partitioning Around Medoids (PAM)" clustering algorithm, the regions are clustered with respect to their price and liquidity development after the average silhouette method is applied to find the optimal number of clusters. The dataset underlying this analysis comprises more than 4.5 million observations in 380 German regions from 2013 Q1 to 2018 Q4. The clusters are then analysed by means of further economic and socioeconomic data in order to identify similarities. Furthermore, the clusters are interpreted from a geographic perspective. We find that the allocation to cluster 1 is always supported by higher growth rates in the variables, population, working population and real GDP, implying higher demand for space. Moreover, in each of the analysed categories cluster 1 reveals a lower unemployment rate as well as a higher disposable income. One of the most interesting implications is, that apparently a large part of the German population has developed into professional real estate investors. In Germany the largest share of landlords is the one of the so-called non-professional landlords. As the regions assigned to cluster 1, displaying the most significant price increase, seem to be chosen based on a very sophisticated market analysis by identifying the regions with the strongest fundamental data, it seems like the dominating market players have significantly increased their knowledge and approach for investing in residential real estate.
\end{abstract}

Keywords Residential · Housing · Liquidity · Index · Time on market · GAMLSS · Cluster $\cdot$ Partitioning around medoids

JEL Classification R2 $\cdot \mathrm{R} 21 \cdot \mathrm{R} 3 \cdot \mathrm{R} 32$

The online version of this article (https://doi.org/10.1007/s11573-020-00990-2) contains supplementary material, which is available to authorized users.

Extended author information available on the last page of the article 


\section{Introduction}

Financial assets such as stocks and bonds are traded in tremendous volumes, turning over billions of dollars within seconds and with almost no spatial constraints. By contrast, the transaction process of direct real estate is more complex, often consuming several months due to the heterogeneity of individual properties and market specific frictions. For example, larger participation-, search- and transaction-costs, as well as considerable asymmetric information impede a smooth match between buyer's or tenant's and seller's or landlord's price expectation within "short" time intervals. When it comes to residential real estate-an asset class which is strongly linked to individual preferences of buyers and tenants as well as expectations of sellers and landlords - a matching of both sides may be even more difficult. Thereby, the location of the respective dwelling plays a major role for the development of the key features determining the matching process.

On the residential real estate market, the process of selling or renting out a dwelling comprises of two essential components. The first component is the introduction of the dwelling onto the market at a price ${ }^{1}$ determined by the seller or landlord. The second component is the time it takes until a prospective buyer or tenant is willing to take the dwelling off the market and to pay the price. ${ }^{2}$ Contingent upon a matching of the expectations of supply and demand, a market is able to operate. The easier, thus faster this matching occurs, the higher the liquidity on the market. Liquidity is related to price in both cause and effect. According to Geltner et al. (2014), increased market activity, displayed by a higher number of transactions as well as a rising transaction frequency on the residential market, leads to more similar properties in the respective market. Hence, the observation of relevant transaction prices becomes easier. As the information of properties being transacted in the relevant market directly influences the individuals' price assessment of other properties, potential market participants become better informed, leading to less market uncertainty. Thus, potential buyers or tenants and sellers or landlords can form improved reservation prices, so that the respective distributions become narrower and converge to the "equilibrium price". 3 Consequently, transaction prices improve and so does liquidity. In the following, liquidity is defined as the inverse of the time on market (TOM). Typically, the matching will occur faster if the price of the dwelling is supported by its particular location and building characteristics. Depending on the level of demand, buyers and tenants might start to accept higher prices. But as long as there is sufficient supply, the prospective buyer or tenant will continue to search the market and not rush into an undesired contractual agreement. Therefore, the buyer or tenant is said to be the provider of liquidity, as he has the financial resources to afford the dwelling and to convert it into cash or a

\footnotetext{
1 In the following, the term "price" refers to the price on the investment as well as the rental market and is distinguished as "price on the investment market" and "price on the rental market".

2 Due to a lack of transaction prices and contract rents on the German residential market the asking price and asking rent, respectively, operate as a "take it or leave it option" to the buyer or tenant and thus price negotiations are not considered as well (see Sect. 3).

3 The "equilibrium price" is defined as the price, where the market clears, leading to maximum transaction volume and maximum liquidity. This is the case, when there is no asset price uncertainty and all potential market participants are perfectly informed.
} 
dividend yielding asset for the owner or landlord, see Fisher et al. (2003). Only if it is up to "take what you can get", buyers and tenants will be accepting a price which is exceeding their initial reservation price in no time.

Currently, the assessment of the real estate market is mainly based on the consideration of prices. Hence, the price development is captured by a variety of indices worldwide, see European Central Bank (ECB), Bank of International Settlements (BIS) and International Monetary Fund (IMF), among others, to assess the state of the residential market. However, not including information about the time it takes to sell or rent out a dwelling might lead to an incorrect assessment of market phases or spatial markets, respectively. To improve the assessment of the residential market, this paper additionally provides quality- and spatial-adjusted liquidity indices for the residential investment and rental market, as complementary demand indices. Hence, this paper aims to provide deeper insights to the under-researched German residential real estate market by combining the consideration of price and liquidity indices. Both indices are developed for the investment and rental market separately for 380 of 401 NUTS 3 regions. The approach is based on the matching of three data sources on an applied big data environment with more than 4.5 million observations, split into about 1.5 million on the investment market and about 3 million on the rental market.

Over the last decade, Germany has experienced a strong and enduring economic expansion. The fundamental economic data exhibits a growing GDP, accompanied by historically high levels of labor demand. The consistently favorable macroeconomic situation and geopolitical events triggered high migration from within the European Union as well as from outside. In addition, the number of households has been increasing due to the social trend towards fewer household members. Furthermore, interest rates for mortgages have been extremely low, resulting in higher affordability of homeownership. Unsurprisingly, this economic and socioeconomic development led to booming demand for residential real estate. Despite rising building permissions and construction activity, building completions have been insufficient to meet demand in many regions. In a study of the Federal Institute for Research on Building, Urban Affairs and Spatial Development (BBSR), Held and Waltersbacher (2015) identified an increased demand of 272 thousand new dwellings per year for the years 2015-2020. The statistics of the Federal Statistical Office (2019a) show that not in a single year since the BBSR published the study, enough new dwellings entered the market (max. 251 thousand in 2018). As consequence, vacancy rates fell below sustainable levels in many regions and house prices as well as rents have experienced upside pressure. The official national house price index of the Federal Statistical Office (2019b) reveals a national price increase of $36 \%$ for the last 6 years. According to the big data sample used for this study, which includes about 1.5 million observations on the investment market, asking prices increased by $44 \%$ on average within the same period. ${ }^{4} \mathrm{~A}$ decomposition of the consumer price index published by the Federal Statistical Office (2019c) reveals an increase in rents of a mere $9.6 \%$ for the last 6 years. Again, the current big

\footnotetext{
4 The difference to the Federal Statistical Office might be caused due to the fact that this paper only covers 380 regions in the sample in order to avoid a bias stemming from inactive markets. The Federal Statistical Office, however, includes all regions, and thus the inactive markets that mostly show relatively weak price developments drag the average price development down. Hence, the Federal Statistical Office exhibits a slightly lower price increase compared to our results.
} 
data sample of more than 3 million rental offers reveals an increase of $14.9 \%$ within the same period.

The price appreciation on the rental market seems innocuous in comparison to the one experienced on the investment market. With a homeownership rate of $43 \%$ as of $2013,{ }^{5}$ the first year covered by the current sample, more than half of the German population rent their homes. While Voigtländer (2009), among others, discussed in detail the reasons for the extraordinarily low homeownership rate, research on the nationwide rental market is rather scarce. Furthermore, the ratio of observations on the rental market to observations on the investment market in this paper is about 2:1 and hence demonstrates the importance of the rental market in Germany. Simply based on the moderate appreciation in asking rents, it is hardly possible to make any inferences with regard to a tight rental market. Are the stories about property viewings with more than 50 competitors for the same flat only urban myths? Maybe the analysis of the liquidity on both residential markets reveals the somehow hidden demand. By only looking at the average change in time on market, it seems as there is only a rather small difference between the investment and the rental market, as the liquidity improved by $50 \%$ and $39.5 \%$ respectively. An estimation of qualityand spatial-adjusted liquidity indices, however, exposes the real difference in market tightness.

However, the price and liquidity development are geographically not equally distributed across the country. A booming trend is mainly observed in the major cities, their surrounding conurbations as well as economically strong regions in southern and north-western parts of Germany. In contrast, rural regions in the east of the country as well as structurally weak regions in the western parts are left behind. Consequently, these areas suffer from the ongoing urbanization and the concomitant rural emigration, leading to low demand and high vacancy rates. Hence, the price and liquidity development differ significantly within Germany. Therefore, it is not sufficient to consider the German market as a whole but to split it up into a regional analysis. That is why, a cluster analysis is conducted in this paper in order to detect economic and socioeconomic similarities and differences of flourishing and fading regions.

The study aims to answer the following questions regarding the residential real estate market.

1. How did price and liquidity on the German residential investment and rental market measured by quality- and spatial-adjusted hedonic indices evolve over the last 6 years?

2. To what extent can the markets be clustered? What similarities and differences in view of economic and socioeconomic indicators do these regions share?

3. Which overall conclusions and implications can be drawn for the German residential real estate market?

The remainder of this paper proceeds as follows: The next section reviews the current state of the literature. Section 3 describes the dataset and the descriptive statistics. Section 4 presents the econometric model, including the derivation of the hedonic

\footnotetext{
5 According to GdW (2016).
} 
price and liquidity indices as well as the clustering algorithm. Estimation results are presented and discussed in Sect. 5. Section 6 concludes.

\section{Literature}

As mentioned above, a deeper understanding of the residential real estate market can only be achieved by examining the price development in combination with the liquidity development. Generally, several liquidity proxies exist for the real estate markets. In line with Sarr and Lybek (2002), Ametefe et al. (2011) summarize various liquidity indicators into five main categories: (1) transaction cost measures, (2) volume-based measures, (3) price impact measures, (4) return-based measures and (5) time-based measures. (1) Transaction cost measures are mainly used for the liquidity analysis on the financial market, see e.g. Clayton and MacKinnon (2000). A market is described as liquid when transaction costs are relatively low. Liquidity is commonly approximated by the spread between the bid and ask price, empirically going back to Demsetz (1968), and related measures. The smaller the spread the more liquid the market. Hence, the bid-ask spread is a measure for market liquidity as well as a transaction cost measure. According to Geltner et al. (2014) the bid price would equal to the asking price, hence, "equilibrium prices" would be charged implying market clearing, if there was a frictionless market with all market participants being perfectly informed about property values. However, when it comes to residential real estate-an asset class which is strongly linked to individual preferences of homebuyers or tenants and expectations of home-sellers or landlords as well as to asymmetric information-both counterparties reveal a different valuation for the same asset. As long as transaction markets are considerably active, both market participants can observe various transaction prices of similar properties. Consequently, they build their beliefs about prices as a distribution around the likely "equilibrium price". Hence, the higher the transaction frequency on the respective market, the closer the spread between the bid price and the asking price, and in turn the higher the liquidity on the market. To apply this liquidity measure to the German residential real estate market, however, is not possible in this paper due to data restrictions regarding bid prices. (2) Volume-based measures depict liquidity as the absolute or relative number of transactions. It is mainly used for the liquidity analysis of listed real estate, see e.g. Brounen et al. (2009), however, e.g. Fisher et al. (2009) apply it on the direct real estate market as well. Volume-based measures comprise the transaction volume, the turnover ratio, the quote size, the number of bids and the market depth. The transaction volume is a very popular measure of liquidity in the literature due to its simplicity and data availability. The transaction volume in a specific period is calculated as the sum over all traded assets (price times quantity of an individual asset) in a specific period. Following Geltner et al. (2014), from a theoretical point of view a higher trading volume implies that the assets are generally more similar and, hence, the information of transactions has a greater impact on the appraisal of other assets. Consequently, the distributions of the reservation price of buyers and sellers are converging, decreasing the bid-ask spread as well as the transaction costs and, thus, leading to higher liquidity. Another commonly used liquidity measure is the turnover ratio, however, due to its calculation (transaction volume divided by the product of existing 
stock and price) is not popular for the direct real estate market as these variables are harder to estimate as e.g. for the stock market. (3) Furthermore, there are different liquidity proxies belonging to the group of price impact measures. These proxies have in common to measure liquidity by separating liquidity from other factors that influence real estate prices. The Amihud (2002) measure for example, applied by Karolyi et al. (2012) as well as Glascock and Lu-Andrews (2013) for instance, is commonly used in the finance literature. Another proxy would be the Pastor and Stambaugh (2003) liquidity factor which is a monthly liquidity measure based on daily data that refers to occasional price changes. (4) Return-based liquidity measures have the advantage that the calculation requires no further information besides the price indices. These measures include for example the illiquidity proxy, developed by Das and Hanouna (2010), which calculates the run length of returns. (5) The liquidity measure used in this paper belongs to the time-based measures. They contain the holding period and the trading frequency, measuring liquidity as the frequency an asset is traded. The holding period, for example applied by Amihud and Mendelson (1986), is empirically applied as the inverse of the turnover rate. For a better suited application in financial markets this liquidity measure was corrected for untraded assets by Collett et al. (2003). Another popular time-based measure is the time on market, measuring liquidity as the time it takes to transact a certain asset. The time on market is especially used in the direct real estate market and is addressed in Krainer (1999) and Allen et al. (2009) among others. The time on market is the measure used in the underlying paper.

As most other markets, the residential real estate market exhibits cyclical movements over time. According to the seminal work of Kluger and Miller (1990) who developed a liquidity measure by using the Cox (1972) proportional hazards model, housing prices and liquidity exhibit a positive correlation. Thus, prices and liquidity should match along "hot" and "cold" market states. Krainer (1999) defines a market as "hot" when prices are increasing, the time on market is short and transaction volume is above average. In contrast, decreasing prices, relatively long selling times and low transaction volumes point to a "cold" housing market. A positive correlation is found in Berkovec and Goodman Jr. (1996) for instance. Follain and Velz (1995) for example, find a negative correlation. While Stein (1995) and Genesove and Mayer (1997) reason the correlation with sellers' equity constraints, i.e. with frictions on the credit market, Krainer (1999) shows that "hot" and "cold" real estate markets emerge due to search frictions and asymmetric information. Cauley and Pavlov (2002) show evidence for the option value of homeowners and for nominal loss aversion. Substantial deviations from these two market states might indicate speculative expectations by investors and landlords, adjustment processes or supply and demand changes. To detect these deviations is essential for real estate market participants, as it is otherwise impossible to reduce the risk in investment decisions.

Literature in the price-liquidity field focuses predominantly on the US residential investment market. At the same time, academic research concerning real estate market movements on the German market is rather scarce. While most of the literature strand focuses on "hot" and "cold" market phases along the residential cycle, this paper aims to detect "hot" and "cold" market spots on a regional basis. As one of the few papers on the German market, an de Meulen and Mitze (2014) identify "hot" and "cold" spots on the Berlin residential market. In order to detect those, the authors exclusively 
investigated the price aspect of dwellings. In general, the movements on the residential real estate market are described primarily with price indices. On the overall German market, there are hedonic price indices provided by the Federal Statistical Office as well as indices provided by private companies like e.g. bulwiengesa ${ }^{6}$ and Immobilienscout24 (IMX). The methodology and data behind the IMX are described in Bauer et al. (2013). However, a complementary liquidity index and a combination between both are missing. As mentioned above, it is precisely needed to look simultaneously at prices and liquidity when understanding the current and future state of residential real estate markets. Especially for central banks, policy makers, institutional investors, and private households it is essential to be aware of the liquidity momentum, as both indices might move in opposite directions, pointing to different market states. Thus, solely considering the price index for classifying a regional market might lead to incorrect investment strategies and policy implications. Therefore, this paper develops a quality- and spatial-adjusted price and a complementary liquidity indicator for the investment and rental market of 380 German regions. According to the indices, the regional housing markets are then clustered in order to reassess the assumption that prices and liquidity move together or whether their dynamic behavior exhibits frictions. For more than 25 years, bulwiengesa has been providing a clustering of German cities according to their size, measured by the number of inhabitants, the size of the office market and the importance of the city for the national as well as international real estate market. Heinrich and Just (2016) have noted, that those characteristics might not be entirely sufficient for concluding that housing markets form a cluster. While the approach of Heinrich and Just (2016) and the one presented in this paper both use clustering methods, the latter one does not directly cluster a variety of variables directly but uses them for the preceding empirical index calculation. In addition to the quality- and spatial-adjusted regional price indices, a liquidity index for each market, respectively, is introduced as an additional clustering indicator. The indexing and clustering on a regional level yields a very granular analysis of the German residential investment and rental market and allows the identification of "hot" and "cold" spots. The findings should be of interest to households, institutional investors and policy makers trying to steer the residential market.

\section{Data and descriptive statistics}

In the underlying paper data is gathered from four data sources. Real estate data, including prices on the investment and rental market, are taken from empirica systems (https://www.empirica-systeme.de), which collects georeferenced real estate data from more than 100 German Multiple Listing Systems (MLS) such as the market leaders ImmoScout, Immonet or Immowelt but also regionally focused market places and newspapers for the whole German market. As the market leader of real estate data for Germany, empirica has an own proprietary algorithm that identifies doubles and harmonises the sample. Furthermore, the number of households and the purchasing

\footnotetext{
6 bulwiengesa is one of the largest independent consulting companies on the real estate market in continental Europe.
} 
power per household on a ZIP basis are obtained from the "Gesellschaft für Konsumforschung" (GfK) for 2017. The geo-shapefiles of the German territory are extracted from Eurostat in order to calculate two spatial gravity variables: the distance to the centroid of the NUTS 3 region and to the ZIP-centroid. Although the ZIP regions are all part of the larger NUTS 3 regions, the correlation of the variables used for this approach is only 0.311 on the investment market and 0.322 on the rental market. After merging the data and calculating the gravity variables, we proceed with the data selection. This paper only focuses on active residential real estate markets with more than 100 observations and more than 40 thousand inhabitants in order to avoid a bias stemming from a lack of observations on the respective market and outliers. Thus, the number of considered NUTS 3 regions is reduced from 401 to 380 as well as the initial sample size of 4,780,585 observations is reduced to 4,645,050 observations. In total, $1,476,592$ observations on the investment market (prices) and 3,168,458 observations on the rental market (rents) in 380 German regions from the first quarter of 2013 to the fourth quarter of 2018 are applied for the estimations. Economic and socioeconomic data for the NUTS 3 regions is gathered from Oxford Economics and is used for the explanation and interpretation of estimation results. The data generating process is depicted in Fig. 1.

This paper exclusively uses asking prices and asking rents. Due to a lack of transaction prices and contract rents on the German residential market the asking price and asking rent, respectively, operate as a "take it or leave it option" to the buyer or tenant and thus price negotiations are not considered as well. On the residential rental market this assumption is plausible as negotiations about the monthly rental payments are rather an exception. Regarding the property market, Shimizu et al. (2012) compare different house prices - asking prices, contract prices and registry prices — on the Japanese housing market. They conclude that for the different house prices and, thus, different datasets there exist differences in the housing price distribution, which can be traced back to quality differences. However, after controlling for quality differences across the datasets no substantial differences between the house price distributions are to observe. Another peculiarity of this study is the application of the total price in Euro of a dwelling offered on the investment market and the total monthly rent in Euro for a dwelling offered on the rental market, although the more popular approach is the utilization of price and rent per square meter. When estimating time on market, we observed that the application of those commonly used variables yields economically incomprehensible relationships for the impact of changes in price (improves liquidity all else equal) and living area (decreases liquidity all else equal) on liquidity. The time on market, is defined as a non-negative continuous variable, measuring the time elapse that a dwelling requires to change its status from being offered on the market to being out of the market in weeks calculated by its start and end date. Typical housing attributes included in this study are hedonic characteristics like "living area", "age" and "number of rooms" as well as binary hedonic characteristics like for example "with balcony", "with parking slot", "with elevator". Since the data is georeferenced, NUTS 3 regions have been employed as geographical analysis units and are defined by Eurostat to the "Nomenclature of Territorial Units for Statistics", which is a hierarchical system for dividing the economic territory in Europe. Hence, this classification provides the possibility of statistical comparison of regions within the EU. NUTS 3 
Generation process of real estate data

Assets are offered via digital marketing channel

Data is collected and harmonised

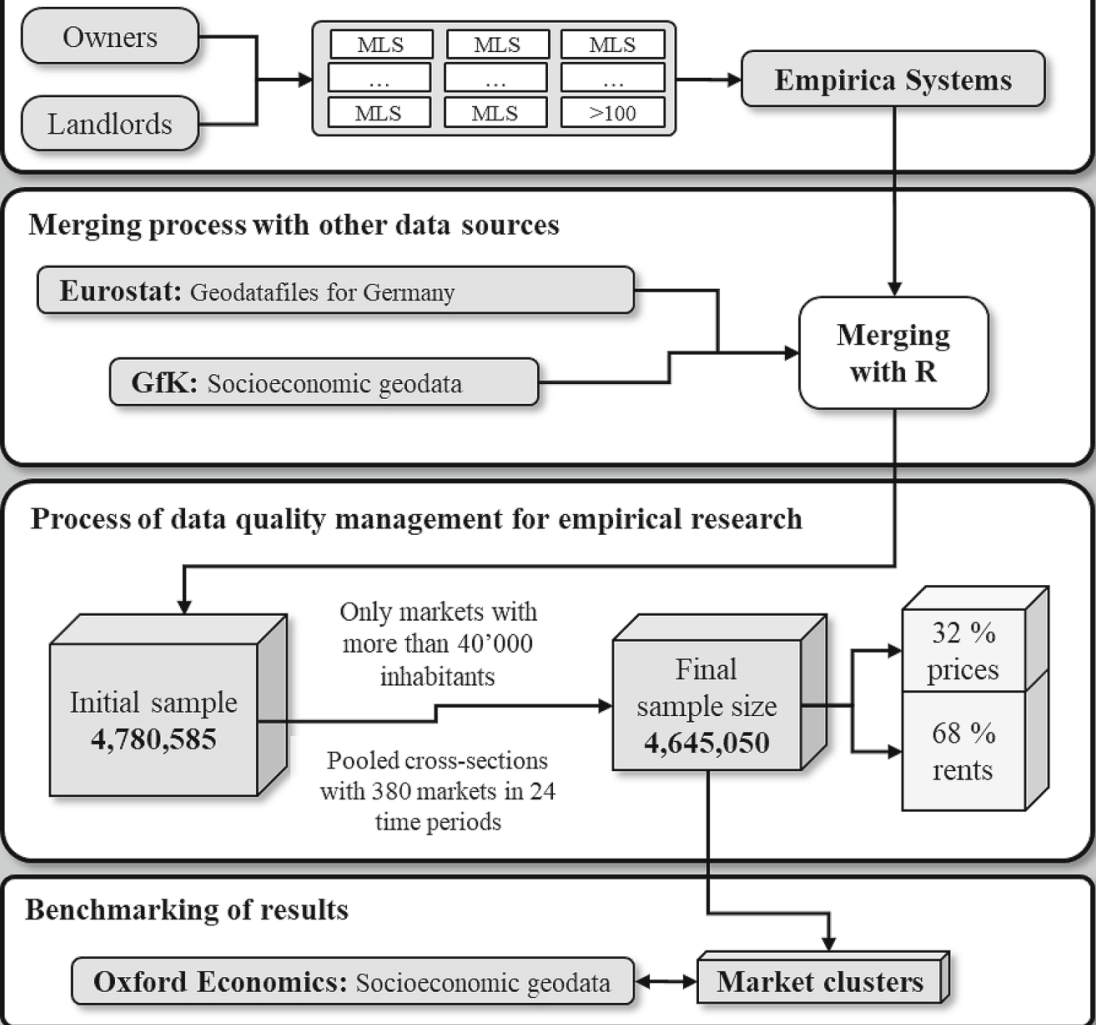

Fig. 1 Generation process of residential real estate data

regions are the smallest classification units, thus cover small regions that are related to counties or administrative districts. This classification of spatial territory is strongly related to the administrative division of the country. Subsidies for specific regions are also assigned according to the classification of NUTS regions. Michels et al. (2011) criticize that this type of classification exhibits the administrative structures, however, cannot depict economic and functional linkages to the surrounding areas. They propose to classify the regional markets into "housing market areas", defined as areas where a household lives and works and within that area the household will search for an alternative place to live in the case of relocation. Hence, Michels et al. (2011) take migration as well as commuting flows into account and make their classification more functional. Even though the classification into "housing market areas" constitutes a very effective approach, it is not applicable to the underlying paper. The aim of this paper is to allocate regions to clusters according to their price and liquidity development and further to detect economic and socioeconomic similarities of these 
regions. Consequently, an official classification is inevitable in order to match the clustered regions to economic and socioeconomic data based on the same regional level. Furthermore, the classification of "housing market areas" might lead to a different classification on the investment and regional market. Hence, this could lead to further complications regarding the underlying paper.

The variables, their units and sources can be found in Table 1 .

Figure 2 shows the cumulative mean price and time on market development on the investment (IM) and rental market (RM) from the first quarter of 2013 until the end of the observation period. It is visible that prices have been increasing accompanied by a diminishing time on market on both markets. Hence, both indicators point to a boom phase on the German housing market, triggered by ongoing demand with supply lagging behind. Moreover, it is observable that prices on the transaction market have been increasing considerably more than rents. While rents have been rising by a mere $14.9 \%$, prices on the transaction market have experienced a substantial growth of $44 \%$ over the last 6 years. Those figures indicate a particularly high demand on the investment market, probably triggered by constantly low mortgage rates on housing loans and a lack of interest-bearing investment opportunities.

It seems that the price development has not yet been fully absorbed by the rental market. The relatively moderate growth in rents seems to only reflect the natural demand, which obviously was higher in cities. As landlords will try to pass on the rising prices on the investment market to their tenants, it might indicate further rental growth in the near future. Of course, rental protection laws prohibit landlords to hand over the entire increase in transaction prices to tenants in order to meet their target return. Asking exorbitant rents has been prohibited on the German market for years, not only since the introduction of rent control in 2015. Because of lacking investment alternatives, new landlords somehow became acquainted to shrinking rental yields. Nevertheless, time on market exhibits an enormous decrease of about $50 \%$ on the transaction market and about $40 \%$ on the rental market with an almost parallel development on both markets. Although prices on the investment and rental market have not experienced growth of equal magnitude, the similar development of time on market indicates considerably high demand on the rental market, which might also result in upward pressure on rents. To reason the similar drop in time on market with relatively more supply on the rental market in relation to the investment market is rather less plausible, as newly built dwellings are usually offered on the investment market, before they appear on the rental market. Thus, this slightly controversial finding emphasizes the importance of focusing on both indicators - price and time on market—when analysing the residential real estate market.

Figure 3 exhibits, that heterogeneity is omnipresent on the housing market. Panel A to D show, that households within different purchasing power percentiles demand a different price, living area, and distance to the city center. Furthermore, it is shown that the sales and letting process with respect to the marketing time varies.

Generally, relatively richer households can afford more expensive dwellings, prefer larger living areas, tend to live further away from the city center and spend less time on the search and matching process. These preferences are visible for the investment as well as the rental market. Surprisingly, buyers living within zip codes with very low purchasing power (20th-, 30th percentile) pay on average higher prices than 


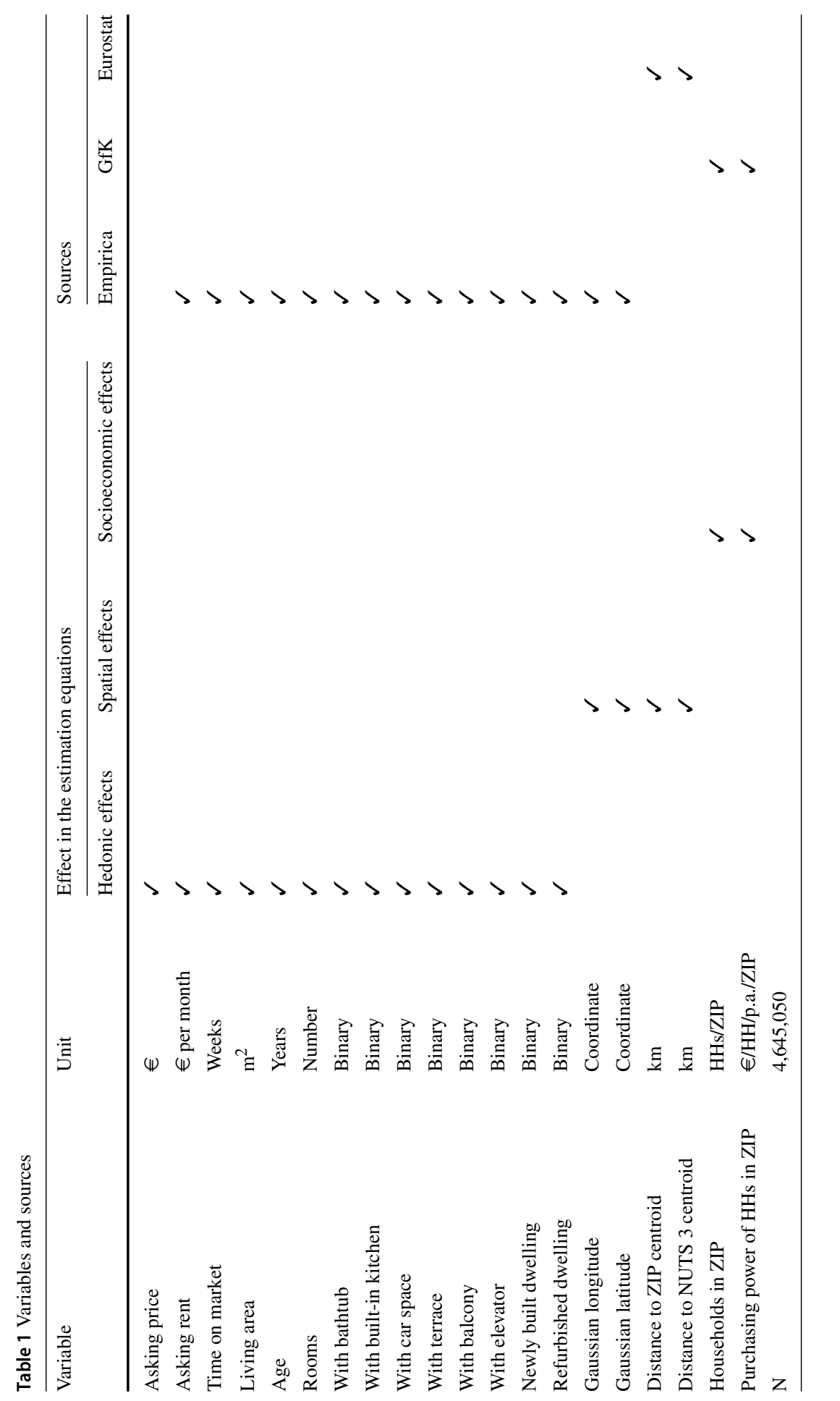


Panel A: Cumulative percentage change in mean price, investment and rental market

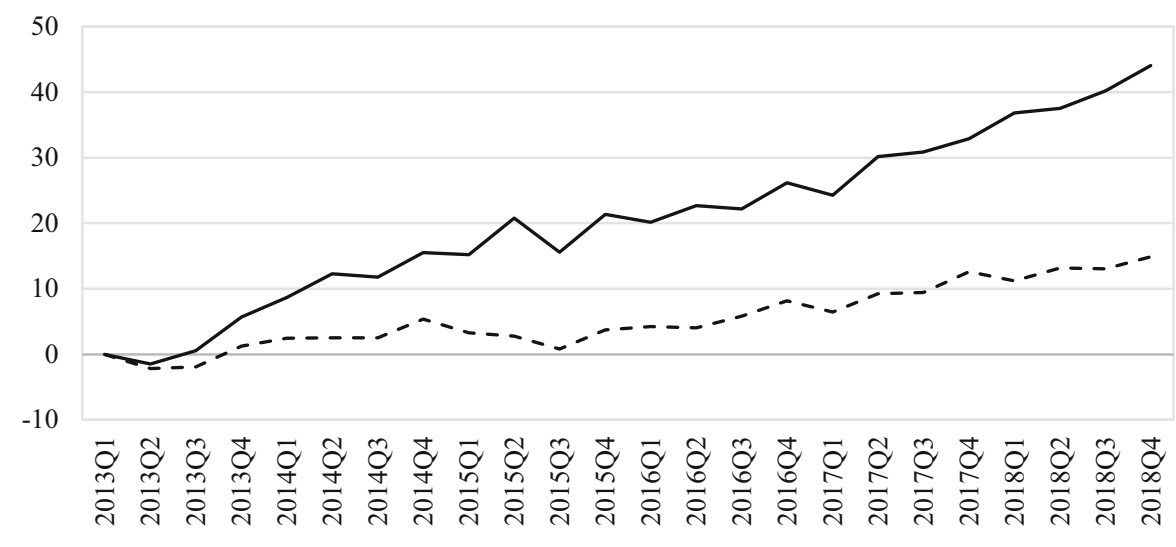

$\longrightarrow \Delta$ price, IM $\quad----\Delta$ price, $\mathrm{RM}$

Panel B: Cumulative percentage change in mean time on market, investment and rental market

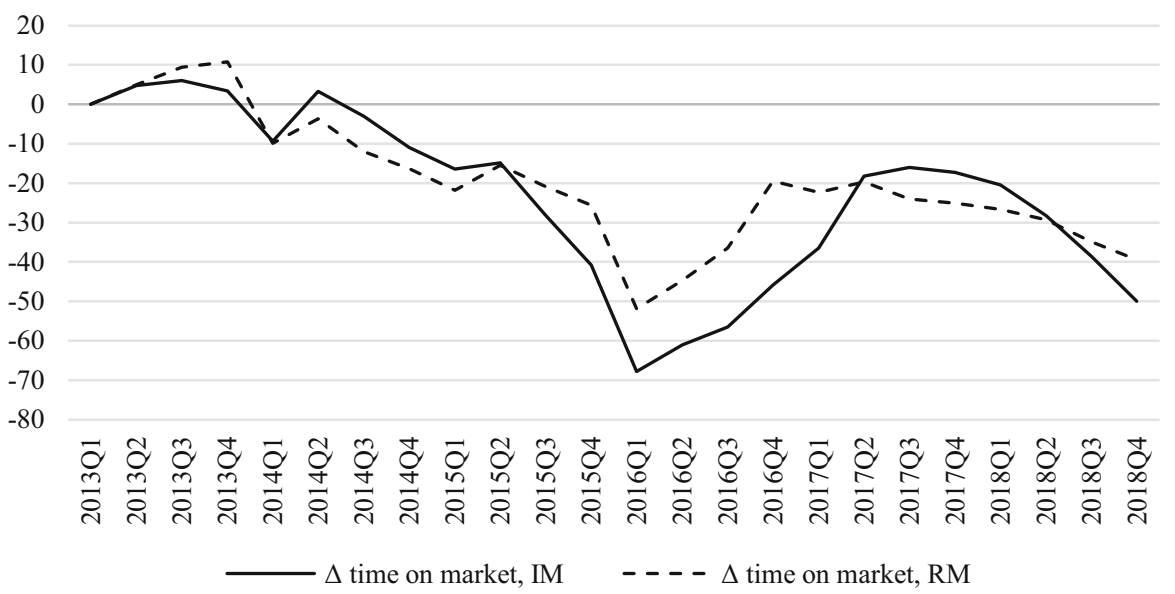

Fig. 2 Cumulative percentage change in mean price and mean time on market. This figure plots the cumulative percentage change in mean price on the residential investment and rental market as well as the cumulative percentage change in time on market on the residential investment and rental market. The data consists of 1,476,592 observations on the residential investment market and 3,168,458 observations on the residential rental market. The sample period is 2013 Q1 to 2018 Q4

the middle-income (40th-, 50th-, 60th percentile) groups. On the investment market a reason for that might be that the living area demanded by households at the 40th and 50th purchasing power percentile is lower than at the 30th percentile and furthermore, these households live further away from the city center. However, this cannot 
Panel A: Price (in $€$, left y-axis) and time on market (in weeks, right y-axis), investment market

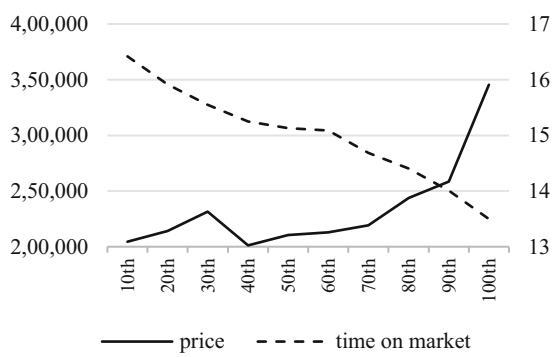

Panel C: Price (in $€$, left y-axis) and time on market (in weeks, right y-axis), rental market

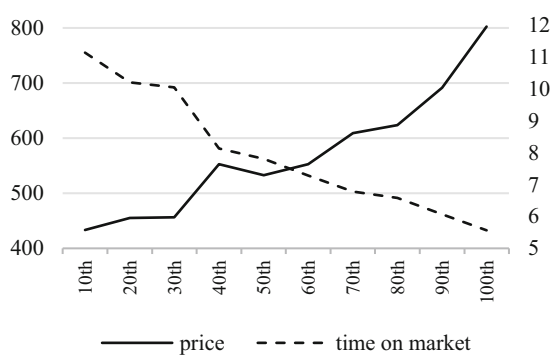

Panel B: Living area (in $\mathrm{m}^{2}$, left $\mathrm{y}$-axis) and distance to NUTS 3 center (in km, right yaxis), investment market

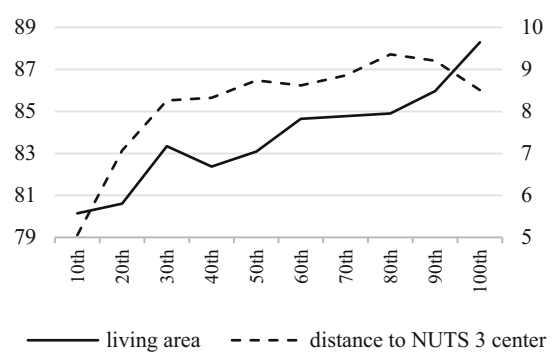

Panel D: Living area (in $\mathrm{m}^{2}$, left y-axis) and distance to NUTS 3 center (in km, right yaxis), rental market

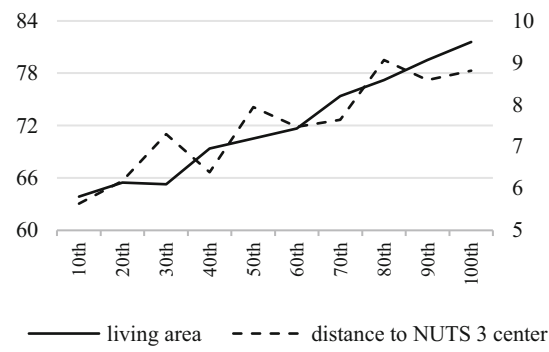

Fig. 3 Distribution of selected variables across purchasing power percentiles. The figures plot the distribution of selected variables segmentd by purchasing power percentiles. The data consists of 1,476,592 observations on the residential investment market and 3,168,458 observations on the residential rental market. The sample period is $2013 \mathrm{Q} 1-2018 \mathrm{Q} 4$

be observed on the rental market. Another interesting fact is, that the range between the highest and lowest income group with respect to prices, living area and time on market is remarkably more pronounced on the rental market relative to the investment market. While on the investment market asking prices, living area and the time on market between the richest and poorest percentile vary by $68.7 \%, 10.2 \%$ and $17.8 \%$, the differences on the rental market are much stronger with $85.3 \%, 27.7 \%$ and $50.1 \%$, respectively. This infers that the participants and probably also the dwellings on the rental market are much more diversified than those on the investment market. It seems surprising, that relatively rich households tend to spend much more on renting than on the investment in a dwelling compared to relatively poor households. Regarding the distance to the city center it is noticeable that especially among the poorest, an increase in purchasing power leads to a very strong shift of investments further away from the city center. 


\section{Econometric approach}

The aim of a price index is to measure the price development over successive periods after correcting for hedonic characteristics. However, residential dwellings are not transacted periodically, but rather irregularly and even infrequently. Furthermore, residential real estate is extremely heterogeneous, both in terms of its physical characteristics and its location. Dwellings with different characteristics and in different locations might exhibit distinct price and liquidity dynamics in terms of volatility and cyclicality. Thus, idiosyncratic price and liquidity movements might be to observe in diverse markets, due to social, and economic circumstances in a particular region. In order to control for heterogeneity, hedonic indexing is applied in this paper. The hedonic approach is a method for generally indexing economic prices of goods affected by quality changes. Kain and Quigley (1970) were among the first to apply hedonic pricing to the real estate market. Given hedonic data, the hedonic model decomposes the price as well as the liquidity of residential real estate into individual characteristics. Hence, the computed index reveals constant characteristics and consequently points out the pure price and liquidity changes over time. The location of a dwelling is probably one of the most important determinants of prices and liquidity. Therefore, not only postcode identifiers as well as longitude and latitude data are considered in the functional form, but the price and liquidity indices are estimated individually for each market $p \in\{1, \ldots, 380\}$, defined by the NUTS 3 regions. In this paper, the time-dummy method is applied, which is defined as the marginal change in price (liquidity) with respect to time. Thus, a transformation of the estimated coefficients of the time fixed effects yields the price (liquidity) index, referring to the percentage marginal change in prices (liquidity) in period $t_{t}$ relative to period $t_{0}$. Hence, the indices can be computed directly from the estimated coefficients. Compared to the imputed hedonic index no "representative dwelling" must be defined and it is less data intensive and therefore very well suited for the construction of regional price and liquidity indices. The standard model for the estimation of a time-dummy hedonic index is given as

$$
y=X \beta+\mu \theta+u \text {. }
$$

As the semi-log functional form has proven appropriate and is used in most hedonic regression models according to Halvorsen and Pollakowski (1981) as well as Diewert (2003), among others, $y$ is an $i$-vector consisting of the elements $y_{i}=\ln \left(p_{i}\right)$. $i$ denotes the number of dwellings in the sample. $X$ is defined as an $(i \times C)$-matrix of covariates, with $C$ being the number of covariates without the time dummies, $\beta$ is a $C$-vector, describing the shadow price of each covariate. To generate an intercept as the first item of $\beta$, the first column of $X$ solely consists of ones. $\mu$ is an $(i \times T-1)$-matrix of time dummies for each period, with $T$ being the number of observation periods, $\theta$ is a $(T-1)$-vector of period shadow prices relative to a fixed time period $t_{0}$, and $u$ is an $i$-vector of error terms. As the purpose is to generate a price index, the coefficient of interest is the time dummy parameter $\theta$. $\theta$ quantifies the time period-specific fixed effects, i.e. the impact of each time period, on the log price after controlling for quality and spatial characteristics of a 
dwelling. Exponentiating the estimated coefficient $\widehat{\theta_{t}}$, yields the time-dummy index as

$$
\widehat{P}_{t}=\exp \left(\widehat{\theta}_{t}\right)
$$

A transformation via $\left[\exp \left(\widehat{\theta_{t}}\right)-1\right] \times 100$ corresponds to the marginal change in prices in $t_{t}$ relative to $t_{0}$. It is to note, that the time dummy index estimated above is not unbiased. According to Goldberger (1968) for example,

$$
\widehat{P_{t}^{*}}=\exp \left(\widehat{\theta_{t}}+0.5\left(\widehat{s e}\left(\widehat{\theta_{t}}\right)\right)^{2}\right),
$$

yields a standard bias correction. $s e\left(\theta_{t}\right)$ refers to the standard error of the timedummy coefficient. However, according to Goldberger (1968) and Syed et al. (2008), among others, the bias is in general very irrelevant with Syed et al. (2008) showing that the difference in the indices appears only in the fourth decimal place. Thus, there is no need to correct for the bias according to Triplett (2004) and de Haan (2010), among others.

As this paper aims to investigate the dynamics of prices and liquidities, four models are estimated in order to obtain the price index on the investment as well as rental market and the two liquidity indices for the investment and the rental market. While for the price indices hedonic regressions are estimated, survival models are set up to obtain the liquidity indices. The four models are estimated individually for each NUTS 3 market $p \in\{1, \ldots, 380\}$ as independently pooled cross-sectional regressions.

\subsection{The residential price index}

This section describes the derivation of the time-dummy price index for the residential real estate investment as well as rental market. The hedonic Eq. (4) is estimated for the investment and rental markets separately based on the approach of Cajias (2018). Estimation is conducted via a semiparametric Generalized Additive Model for Location, Scale and Shape (GAMLSS) introduced by Rigby and Stasinopoulos (2005). The main reason for the usage of the GAMLSS approach is the fact that prices on the real estate investment and rental market vary across space, time and within submarkets. The approach models the parameters of the response as semiparametric functions of the covariates and expands the regression equation by considering the four moments of the response - the mean, variance, skewness and the kurtosis - in the optimization algorithm. The GAMLSS approach is widely recognized and used by international institutions such as the International Monetary Fund, the World Health Organization or the European Commission. The models are parameterized for the price as follows:

$$
\ln \left(P_{i j t}\right)=X_{i} \beta+Z_{j t} \alpha+\mu_{t} \theta_{t}+u_{i j t}
$$

The hedonic regression decomposes the log price $P$ of a dwelling $i$ in ZIP-code $j$ and in observation period $t$ into dwelling-specific characteristics $X_{i}$ and ZIP-code- 
specific covariates $Z_{j t} \cdot{ }^{7} \mu_{t}$ captures the time fixed effects, thus is the focus of the index calculation. The error term $u_{i j t}$ describes the variation in prices that cannot be explained by the model. In this case independently and identically distributed $(u \sim$ iid $)$ robust standard errors are used for the regression. As the time dummy index is defined as the marginal change in price $P_{i j t}$ with respect to $\mu_{t}$, a transformation of the estimated coefficients $\widehat{\theta_{t}}$ according to

$$
\widehat{P I}_{t}=\left[\exp \left(\widehat{\theta}_{t}\right)-1\right] \times 100,
$$

yields the price index $P I_{t}$, referring to the percentage marginal change in prices in period $t_{t}$ relative to $t_{0}$.

\subsection{The residential liquidity index}

Without any doubt the leading model for the analysis of survival data is the Cox (1972) proportional hazards model (PHM). This model is used for exploring the determinants of the duration of an event or elapse of time, e.g. it determines the variables that accelerate or restrict the elapse of time that a response variable needs to change its state. In this case, the response variable is defined as a non-negative continuous variable, measuring the elapse of time that a dwelling requires for changing its status from being offered on the market into being out of the market in weeks, i.e. time on market. For understanding and estimating survival data, two main functions are essential: the survival function $S(t)$ and the hazard rate function $\lambda(t)$. The survival function specifies the probability that an event has not occurred until a certain time $t$ and is formally defined as

$$
S(t)=P(T \geq t)=1-F(t)=\int_{t}^{\infty} f(x) d x,
$$

with $f(x)$ being the probability density function of the time until the event. The hazard function $\lambda(t)$, in contrast, describes the probability at $t$ that an event occurs at time $T$, given that the event has not occurred before and is given by

$$
\lambda(t)=\lim _{\Delta t \rightarrow 0} \frac{P(t \leq T<t+\Delta t \mid t \leq T)}{\Delta t} .
$$

The relationship between those two functions is straightforward since the integrated hazard rate $\Lambda(t)=\int_{0}^{t} \lambda(x) d x$ can be expressed as the negative log of the survival rate $S(t)$ as $\Lambda(\mathrm{t})=-\log S(t)$. In other words, the survival function expresses the probability of a dwelling for staying in the market while the hazard function measures the risk of the same dwelling for leaving the market.

\footnotetext{
7 Since the correlation of the variables "living area" and "number of rooms" is at about 0.6 , we decided to analyze whether the inclusion of both variables improves the explanatory power of the regressions estimating the price and liquidity indices. The results show that the explanatory power decreases by $8-14 \%$ for the different indices if only "living area" is included.
} 
The Cox PHM estimates the survival function, but coefficients can be transformed to hazard rates, giving the probability of "mortality" per unit of time, and hence describing a liquidity indicator. The semiparametric Cox proportional hazards regression is parameterized as

$$
\lambda\left(\tilde{t}_{i j t}\right)=\tilde{X}_{i} \tilde{\beta}+Z_{j t} \tilde{\alpha}+\mu_{t} \tilde{\theta}_{t}+e_{i j t}
$$

The time on market $\tilde{t}$ of a dwelling $i$ in ZIP-code $j$ and in observation period $t$ is decomposed into dwelling-specific characteristics $\tilde{X}_{i}$ and ZIP-code-specific covariates $Z_{j t}$. In addition to $X, \tilde{X}$ includes the $\log$ of asking prices as the data generating process (DGP) of the time on market $\tilde{t}$ is influenced by the initial asking price, as landlords set the asking price when offering the dwelling in the MLS. As in the hedonic survival regression, time fixed effects $\mu_{t}$ are included and $e_{i j t}$ describes the error term. With $\exp \left(\tilde{\theta}_{t}\right)$ being defined as the hazard rate, the estimated coefficients $\widehat{\tilde{\theta}_{t}}$ can be transformed into the liquidity index $L I_{t}$ according to

$$
\widehat{L I}_{t}=\left[\exp \left(\tilde{\theta}_{t}\right)-1\right] * 100,
$$

referring to the percentage marginal change in the hazard rate, i.e. in liquidity, in period $t_{t}$ relative to $t_{0}$.

\subsection{Cluster analysis}

In order to determine regional markets that coincide according to their market movements, proceeding from the price and liquidity indices, the 380 regions are assigned to one of two clusters. The clustering is conducted separately for the price and liquidity indices on the transaction and rental market. Hence, the clustering is conducted on four sub-datasets. The aim of the cluster analysis is to assign regions to the same cluster, so that the dissimilarity within a cluster is minimized and maximized between the clusters. Therefore, the "partitioning around medoids (PAM)" clustering algorithm, going back to Kaufman and Rousseeuw (1987), is applied. The PAM clustering algorithm belongs to the $k$-medoids clustering procedure, that is closely related to the $k$-means procedure, however, according to Kaufman and Rousseeuw (1990), is more robust to outliers and noise. While the $k$-means algorithm aims to minimize the sum of squared Euclidean distances, the $k$-medoids algorithm minimizes the average dissimilarity between the "representative" object, i.e. the medoid, and all other objects of the respective cluster. As with all partitioning methods, the PAM clustering algorithm requires to specify the number of clusters $k$ a priori. Similar to Just et al. (2019) at first the optimal number of clusters is identified. According to Kaufman and Rousseeuw (1990), in this study the average silhouette method, providing an evaluation of the quality of a clustering, is applied. It identifies how well each observation fits into a cluster. This approach computes the average silhouette of observations for several different numbers of clusters. The number of clusters where the average silhouette width is maximized is optimal. For each of the four sub-datasets used in this paper the optimal number of clusters is two. The PAM algorithm consists of two major steps, the BUILD phase and the SWAP 
phase. At first, $k$ initial objects are selected as medoids, i.e. these objects minimize the sum of the distances to all other objects. Second, the objective is to optimize the set of medoids. Therefore, each pair of medoid and remaining object is exchanged. If a swap indeed improves the cluster quality, the initial medoid and the other object change positions. This iteration is conducted until the quality of each cluster is optimal. The stability of the cluster solution provided by the PAM algorithm is assessed via bootstrap. The clusterwise Jaccard similarities suggest that each cluster is stable. The decisive variables underlying the clustering procedure are the estimated time-dummy coefficients $\theta_{t}$ and $\tilde{\theta}_{t}$ at each observation period $t$. Based on this clustering analysis it is the aim of this paper to identify "hot" and "cold" regions as well as regions expected to ascend and descend in terms of price development.

\section{Regional cluster results}

\subsection{Cluster results on the investment market}

After estimating the price and liquidity indices for the 380 NUTS 3 regions, each region is assigned to one of two clusters according to the methodology described in Sect. 4.3. Berlin for example, is assigned to cluster 1 for its price development and cluster 2 for its liquidity development. In the following, the city will be referred to as Berlin $(1,2) .^{8}$

The trend of the quality- and spatial-adjusted price cluster means is shown in Fig. 4 and reveals the cumulated average price change of all dwellings allocated to the specific price clusters, indexed to zero in 2013 Q1. While NUTS 3 regions allocated to price cluster 2 experienced slightly decreasing prices compared to the base quarter at the beginning and started to increase from 2014 Q1 onwards, for price cluster 1 a consistently positive price development is visible. However, over the entire observation period both price clusters display a quite similar upward-sloping trend. Over the past 6 years, prices in price cluster 2 have been rising on average by $32 \%$ and in price cluster 1 even by $56.75 \%$. As the price development in price cluster 1 is much steeper, these regions can be identified as highly demanded regions relative to regions allocated to price cluster 2 .

Comparing regions assigned to price cluster 1 versus regions assigned to price cluster 2 by means of economic and socioeconomic data shows, that at the median ${ }^{9}$ regions in price cluster 1 are larger with respect to the population as well as the working population. An even more pronounced trigger of the very strong price development in price cluster 1 might be the positive development of the population and working population over the whole observation period. Price cluster 1 regions experienced a $3.84 \%$ increase in population and working population rose by $2.5 \%$. This definitely implies a higher demand for living space within the respective regions, resulting in higher prices. In contrast, price cluster 2 regions only had a very small increase in population of $0.97 \%$ and even suffered a loss of $0.91 \%$ in working population. This

\footnotetext{
8 A full list containing the classification of the 380 NUTS 3 regions is available upon request.

9 The median is used instead of the mean in order to prevent outliers from distorting the cluster values.
} 


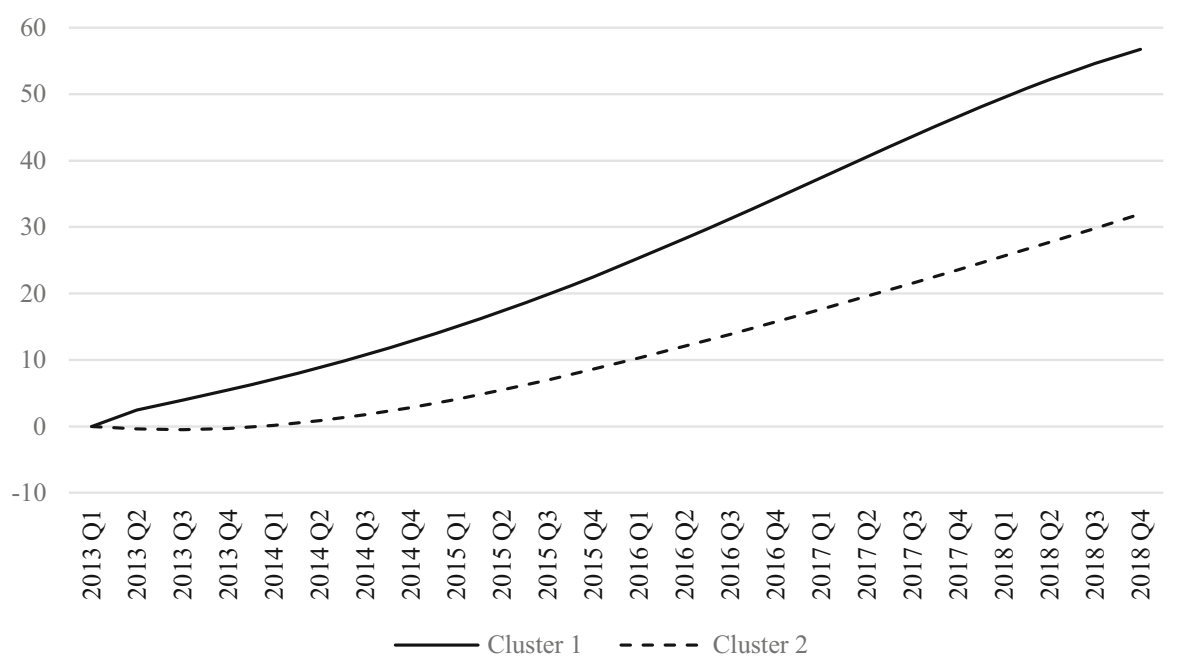

Fig. 4 Price index, investment market. The figure plots the mean cumulative percentage price change for dwellings allocated to the individual price clusters. The price changes are presented as the coefficients of the time dummy variable of a quality- and spatial-adjusted GAMLSS regression. To cluster the index values, the partitioning around medoids (PAM) algorithm was used. The data consists of 1,476,592 observations on the residential investment market. The sample period is 2013 Q1-2018 Q4

very small increase in demand might to some extent be responsible for the lower price development in price cluster 2. However, as prices in price cluster 2 have also been rising not negligibly, other price drivers than the pure demand for space must be an issue. Regions allocated to price cluster 1 are furthermore characterized by a higher real GDP, lower unemployment rates and a higher disposable household income compared to price cluster 2 . While in 2018 the median real GDP in price cluster 1 was about $€ 5.2$ million, regions in price cluster 2 only had a median real GDP of $€ 4.3$ million. It is not surprising, that prices have had a larger growth in more productive regions as this factor is a strong demand indicator and thus correlates with population changes. From 2013 to 2018 real GDP growth is observed for both price clusters, with the median real GDP in price cluster 1 increasing by $10.3 \%$ and $8.42 \%$ in price cluster 2 . The generally flourishing economic conditions can also be observed by decreasing unemployment rates and increasing disposable household income. While the unemployment rate of $2.67 \%$ in price cluster 1 is lower than in price cluster 2 with $3.28 \%$, it is to note that the decline in the unemployment rate is more pronounced in price cluster 2 . The same is to observe for the disposable household income. While the median disposable household income of $€ 48.43$ thousand in price cluster 1 is higher than in price cluster 2 with $€ 43.29$ thousand, the increase in price cluster 2 is stronger. The relatively stronger development of the unemployment rate and the disposable household income in price cluster 2 is not surprising, as these regions started with relatively weak levels for the calculation of the growth rates. The relative strong decrease in the unemployment rate in price cluster 2 and the relative strong increase in disposable household income in combination with real GDP growth might somehow indicate that smaller regions, in terms of population, with still very low disposable household income are in the 
progress of slowly adjusting to the larger and economically stronger regions. This favourable economic development in rather small regions contributed to the upward sloping price development in price cluster 2 without strong gains in population and working population. There is no doubt that the prevalent situation on the investment market in general, with very low mortgage rates and sparse alternative investment opportunities played a significant role for the overall positive price development.

Assigning the regions to clusters by their liquidity development, which is based on the time it takes to sell a dwelling within the respective regions, displays a different pattern but also higher index values at the end of the observation period. As shown in Fig. 5, for regions assigned to liquidity cluster 2, liquidity was worse than in the base quarter in 14 out of 23 quarters. From 2014 Q1 onwards liquidity in liquidity cluster 2 was declining, i.e. marketing time in the respective regions was getting longer. Liquidity hit the bottom in 2016 Q2, exceeded the level of the base quarter in 2017 Q4 and finished with a plus of $45.48 \%$ in 2018 Q4. Regions assigned to liquidity cluster 1 experienced a similar process. Though liquidity in liquidity cluster 1 never declined below the level of the base quarter, it was rather stagnating from 2014 Q1 until the end of 2016. The stagnating liquidity development might to some extent be caused by the sharp increase in building completions between 2013 and 2016. According to the Federal Statistical Office (2019a) building completion of dwellings has been rising from about 188 thousand in 2013 to about 236 thousand in 2016. As in this period the high demand for dwellings faces increased supply, liquidity remains rather constant. Afterwards liquidity experienced a sharp increase, finishing with a plus of $75.05 \%$ in 2018 Q4. Hence, over the entire observation period dwellings became on average more liquid in both liquidity clusters.

Taking a look at the economic and socioeconomic data of the considered regions, it is to observe, contrary to the price clustering, that liquidity was increasing most in regions with a lower median population as well as working population. The difference in population between liquidity cluster 1 and cluster 2 is way less pronounced than between the price clusters. The growth rates of these two variables, however, support the relative stronger liquidity growth in liquidity cluster 1 . While the population in liquidity cluster 1 rose by $3.39 \%$ and the working population by $2.14 \%$, liquidity cluster 2 experienced a rather small increase of $1.66 \%$ and $0.1 \%$, respectively. As the plus in population generates more demand for space, the housing market gets tighter, hence the time it takes to sell a dwelling has been decreasing. In line with population, regions allocated to liquidity cluster 1 show a slightly smaller real GDP of $€ 4.66$ million compared to liquidity cluster 2 with $€ 4.76$ million. In comparison with price clustering, liquidity clustering results in way more similar clusters with respect to real GDP. The change in real GDP, that is more decisive when it comes to liquidity development, is higher in liquidity cluster 1 with $10.5 \%$ compared to liquidity cluster 2 with $8.79 \%$. As with the price clustering these productivity gains coincide with the population development and hence result in higher demand for space leading to higher liquidity levels. For the unemployment rate, household disposable income as well as the respective growth rates the same picture as with price clustering is to observe. The increase in liquidity was stronger in regions with a lower unemployment rate and a higher disposable income. However, what might have triggered the liquidity growth in liquidity cluster 2 , though new demand for space in terms of population 


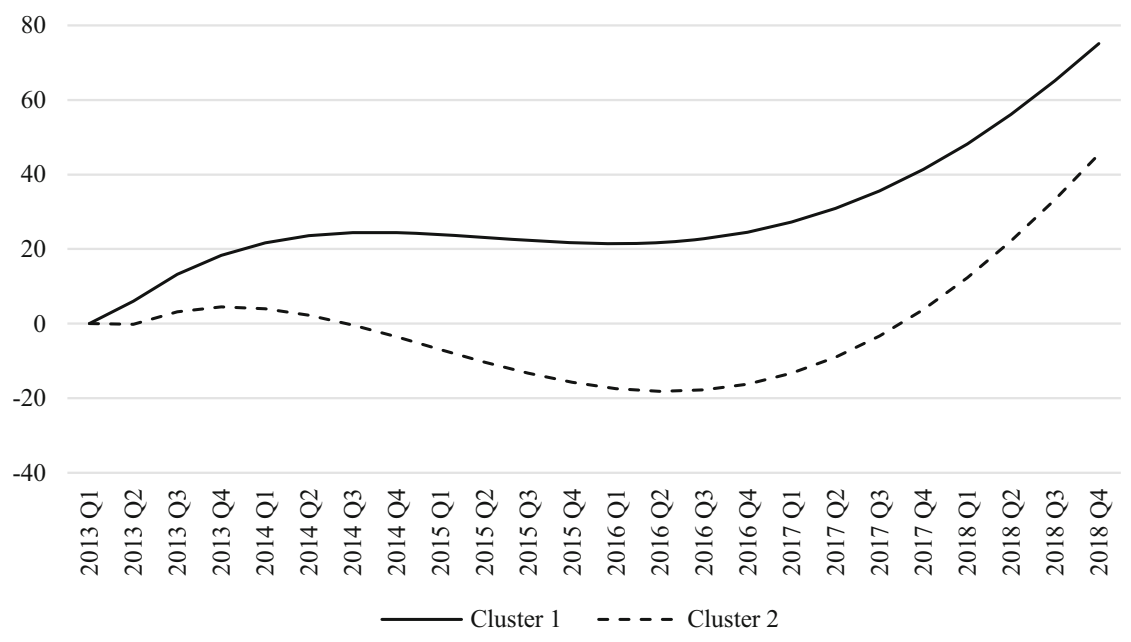

Fig. 5 Liquidity index, investment market. The figure plots the mean cumulative percentage change in liquidity for dwellings allocated to the individual liquidity clusters. The changes are presented as the coefficients of the time dummy variable of a quality- and spatial-adjusted Cox proportional hazards model. To cluster the index values, the partitioning around medoids (PAM) algorithm was used. The data consists of 1,476,592 observations on the residential investment market. The sample period is $2013 \mathrm{Q} 1-2018$ Q4

gains was relatively weak, was the pleasant development of the unemployment rate and disposable household income.

As mentioned above, a combination of the cluster ranks derived from the price and liquidity development is used in order to classify the 380 regions. For this purpose, the price cluster rank is regarded as the primary determinant and the liquidity cluster rank as the complementary secondary determinant, which enables a higher granularity in the classification and a more precise market assessment. Out of the 199 regions allocated to cluster 1 by price, 109 are as well allocated to liquidity cluster 1 . Those regions can be declared as absolute "hot" markets, where an extraordinary price development is supported by a very strong liquidity development. The 128 regions assigned to cluster $(2,2)$ are characterized as "cold". Cluster $(1,2)$ as well as cluster $(2,1)$ can be found in the middle. Figure 6 summarizes the economic and socioeconomic data for the four possible cluster combinations on the investment market.

It is to observe that population and working population are the highest in regions with a relative weaker liquidity development irrespective of the price cluster, i.e. clusters $(1,2)$ and $(2,2)$. These two clusters, however, also exhibit the highest unemployment rates. Real GDP is highest in regions with a relative high price development regardless of the liquidity cluster. Regions with a relative weaker price development combined with a strong liquidity development, i.e. cluster $(2,1)$, are characterized as the smallest in terms of population, working population as well as real GDP. The population and working population development clearly show the demand effect on price and liquidity. The real GDP development shows a very similar picture. The strongest population increase is to observe in regions that exhibit the strongest price 


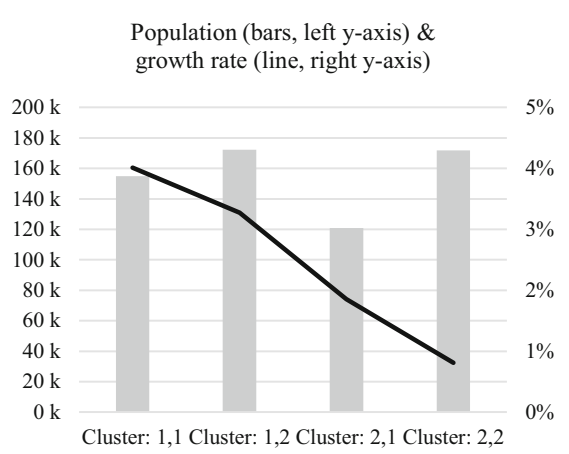

Real GDP (bars, left y-axis) \& growth rate (line, right y-axis)

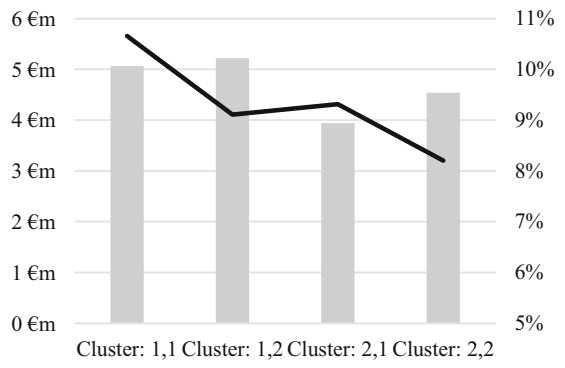

HH disposable income (bars, left y-axis) \& growth rate (line, right y-axis)

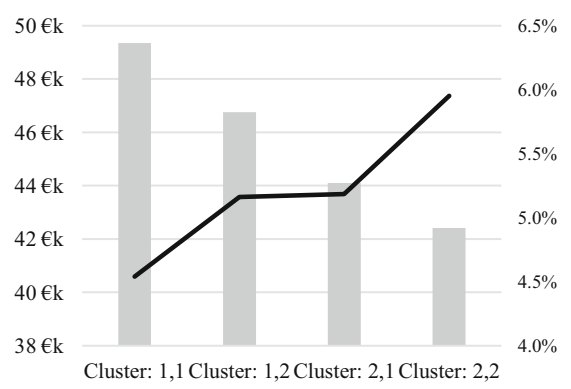

Working population (bars, left y-axis) \& growth rate (line, right y-axis)

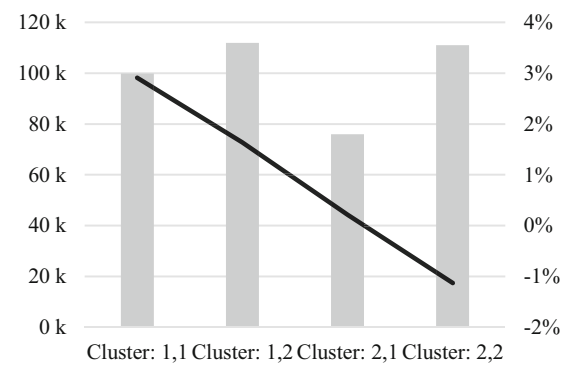

Unemployment rate (bars, left y-axis) \& growth rate (line, right y-axis)

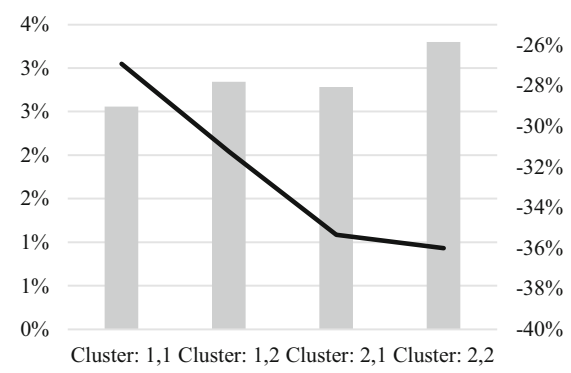

Fig. 6 Socioeconomic data by cluster affiliation, investment market. The figure displays the socioeconomic data by cluster on the investment market. The NUTS 3 regions are allocated to a specific cluster by applying the partitioning around medoids (PAM) algorithm on the price and liquidity index values, respectively. The grey bars exhibit the actual values of the respective variables, labelled on the left $y$-axis. The black lines display the respective growth rates and are labelled on the right $y$-axis. The data consists of $1,476,592$ observations on the residential investment market. The sample period is 2013 Q1-2018 Q4

and liquidity increases. Hence, more productive regions attract more people what in turn leads to more demand for space and consequently results in higher prices and higher liquidity. This is the case if the supply side cannot keep up. In contrast, the "cold" markets experienced the weakest population growth. It is also to observe that 
population as well as working population growth is more pronounced in cluster $(1,2)$ than in cluster $(2,1)$. This might indicate that population growth has a stronger impact on the price development than on the liquidity development. Furthermore, the "hot" regions reveal the lowest unemployment rate as well as the highest disposable income. Especially the household disposable income exhibits a strong variation between the clusters. While cluster $(1,1)$ displays a median disposable household income of $€ 49.34$ thousand, cluster $(2,2)$ achieves only $€ 42.41$ thousand. However, it seems as if the poor performing regions are trying to catch up. With a decline in the unemployment rate of $36 \%$ and an increase in disposable household income of $5.95 \%$, cluster $(2,2)$ regions are the best performers with regard to these two variables.

Regarding the spatial distribution of the clusters, as shown in Fig. 7, a strong concentration of regions allocated to cluster $(1,1)$ and cluster $(1,2)$ in the southern part of Germany emerges. While for Baden-Württemberg, Bavaria and south Hesse $90 \%$, $70 \%$ and $85 \%$ of all regions are allocated to price cluster 1, the clustering approach displays a different distribution for the northern part of the country.

On the investment market, it seems like metropolitan areas with a prosperous economic outlook backed by strong fundamental data have large spillover effects on the surrounding regions, impacting their price and liquidity development. This effect can be observed for Berlin, Frankfurt, Hamburg, Hannover and Rostock. The increased demand for ownership in regions next to metropolitan areas might be caused by the increasing unaffordability of ownership within those metropolises and their outskirts.

Not surprisingly the share of eastern German regions is higher in price and liquidity cluster 2. The strongest concentration of eastern German regions allocated to price and liquidity cluster 2 can be found along the Czech and the Polish border. Of all eastern German regions represented in the sample, $61 \%$ are allocated to price cluster 2 , while $67 \%$ are allocated to liquidity cluster 2 . A similar pattern emerges for economically underdeveloped regions as defined by the Federal Ministry for Economic Affairs and Energy (2016), based on socioeconomic data like income and unemployment and the availability of infrastructure. Of those regions $68 \%$ are allocated to price cluster 2 and $67 \%$ to liquidity cluster 2 . Since a proportion but not all of those regions are located in eastern Germany, a further geographical segmentation seems worthwhile. Interestingly, a majority of the economically underdeveloped regions which are assigned to price and liquidity cluster 1 is located in eastern Germany. This might be due to the fact that the price increase in more rural areas like those around Berlin and Rostock came only after the cities themselves became unaffordable and a large number of people began to demand dwellings which did not participate in a price rally beforehand. The western regions allocated to cluster $(2,2)$ correspond very well to the regions defined as economically underdeveloped. Those are in particular the Ruhr Area which still suffers from the decline of its heavy industry, and the remote regions around the Emsland, in the far northwest of the country, and the regions close to the Danish border.

\subsection{Cluster results on the rental market}

Figure 8 shows the average cumulated change in quality- and spatial-adjusted prices on the rental market for the dwellings allocated to the respective price clusters. The price 


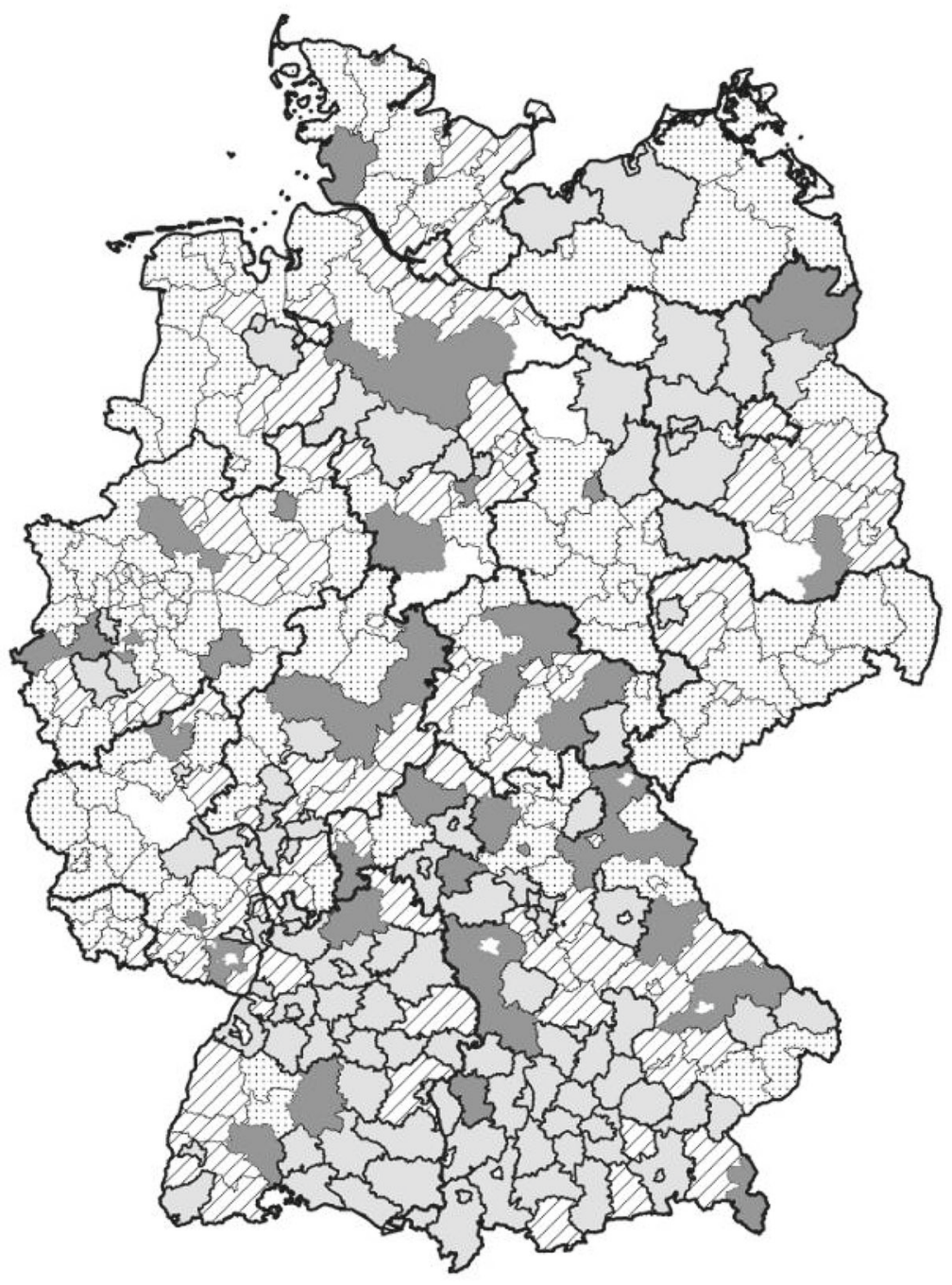

\section{Cluster affiliation}

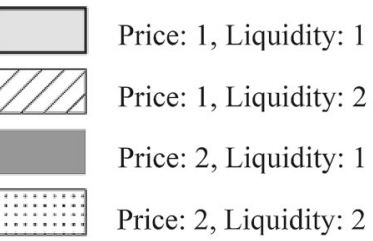

Fig. 7 Allocation of NUTS 3 regions to price and liquidity clusters, investment market. The figure displays the geographic distribution of the individual clusters. The NUTS 3 regions are allocated to a specific cluster by applying the partitioning around medoids (PAM) algorithm on the price and liquidity index values. The data consists of 1,476,592 observations on the residential investment market. The sample period is 2013 Q1-2018 Q4 


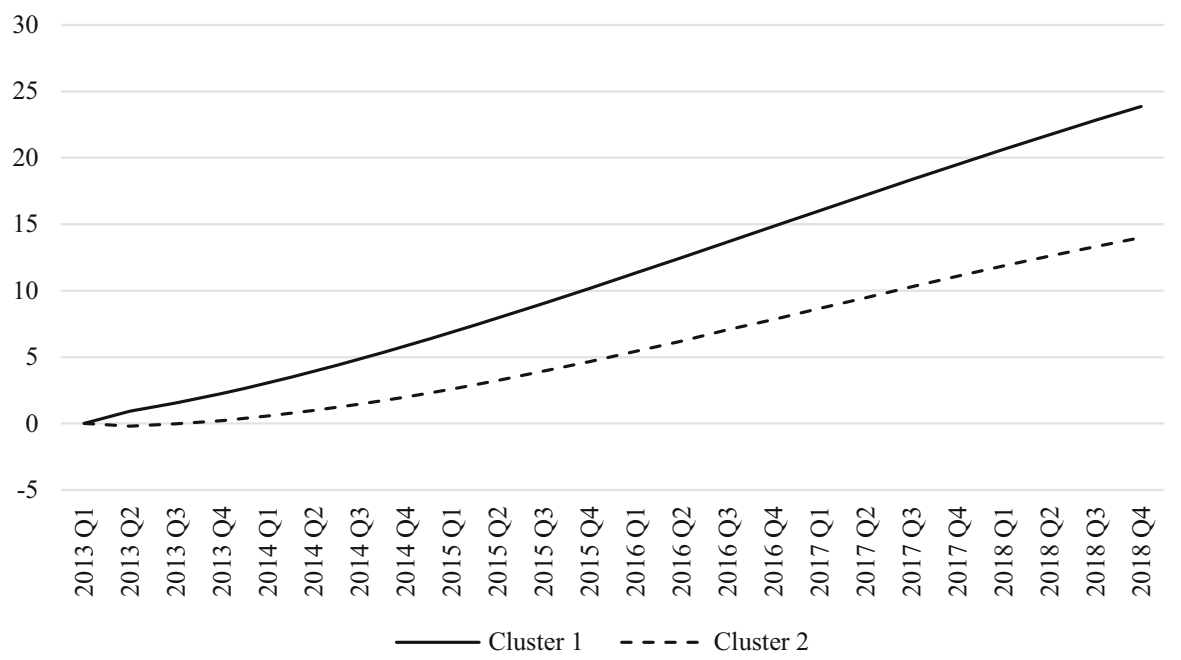

Fig. 8 Price index, rental market. The figure plots the mean cumulative percentage price change for dwellings allocated to the individual price clusters. The price changes are presented as the coefficients of the time dummy variable of a quality- and spatial-adjusted GAMLSS regression. To cluster the index values, the partitioning around medoids (PAM) algorithm was used. The data consists of 3,168,458 observations on the residential rental market. The sample period is 2013 Q1-2018 Q4

clusters on the rental market do not necessarily contain the same regions as the price clusters on the investment market. Price cluster 1 sets itself apart by a very strong and consistently positive development. Nevertheless, the final index value of 23.86 is even less than half of the final index value for the respective quality- and spatial-adjusted price cluster on the investment market, underlining the generally stronger increase in prices on the investment market than on the rental market. The rental market price index in price cluster 2 shows a very similar development. While it has been slightly decreasing compared to 2013 Q1 for the following two quarters, an upward sloping trend is visible from then on. The increasing development is a lot weaker compared to price cluster 1 but nevertheless finishes with an increase of $14 \%$.

The liquidity development on the rental market depicted in Fig. 9, however, clearly distinguishes itself from the investment market. After a one-period drop in the first quarter, liquidity in liquidity cluster 1 was steadily rising until it climaxed in 2017 Q4 with $85.95 \%$ above the base quarter level and afterwards fell to $55.1 \%$ at the end of the observation period. Liquidity cluster 2 decreases relative to the base quarter until 2014 Q1 and from then a slight upward trend is visible until 2017 Q4. A small decline in liquidity in liquidity cluster 2 is apparent in 2018. At the end of the observation period liquidity cluster 2 finishes with an increase of $26.39 \%$ above the baseline level. As with prices the total liquidity growth is much weaker on the rental market compared to the investment market.

The NUTS 3 regions assigned to price cluster 1 experienced a relative strong increase in prices compared to price cluster 2 . At the median they are characterized by relatively low numbers with regards to population, with 143.15 thousand inhabitants in price cluster 1 compared to 169.28 thousand in price cluster 2 , as well as working 


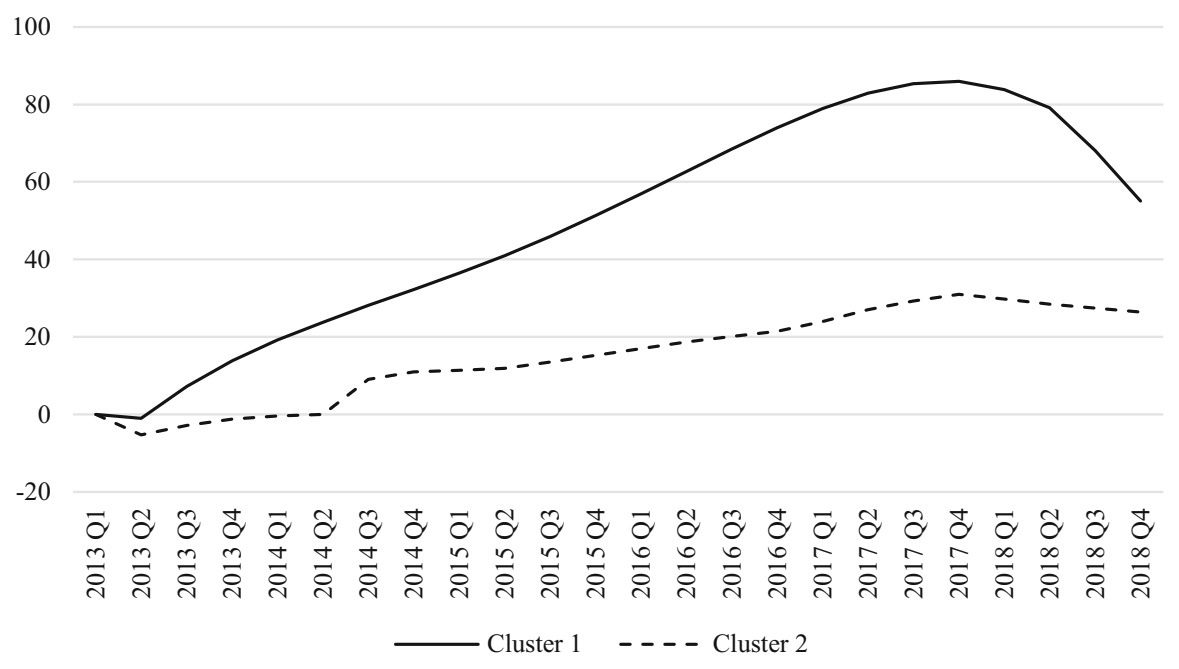

Fig. 9 Liquidity index, rental market. The figure plots the mean cumulative percentage change in liquidity for dwellings allocated to the individual liquidity clusters. The changes are presented as the coefficients of the time dummy variable of a quality- and spatial-adjusted Cox proportional hazards model. To cluster the index values, the partitioning around medoids (PAM) algorithm was used. The data consists of 3,168,458 observations on the residential rental market. The sample period is 2013 Q1-2018 Q4

population. In terms of GDP, however, regions in price cluster 1 exceed the regions in price cluster 2 . Thus, strong rental growth can be observed in the relatively small but economically productive regions. The difference in GDP to price cluster 2, however, is way less pronounced compared to the investment market. Regions allocated to price cluster 1 are further characterized by lower unemployment rates and a higher disposable income of $€ 49.14$ thousand compared to $€ 43.69$ thousand in price cluster 2. A possible driver of the rental growth from 2013 Q1 to 2018 Q4 might be the rising demand for living space, stemming from the increasing population as well as working population. While population in price cluster 1 increased by $3.78 \%$, price cluster 2 only had a growth of $1.3 \%$ and working population even declined. To summarize so far, price cluster 1 seems to obtain regions with a promising future. As on the investment market price cluster 2 experienced a slightly stronger decline in unemployment rates and a stronger increase in disposable household income. But why did liquidity evolve in such different paths on the investment and rental market in the years 2014 to 2017 ? Besides the increased level in building completions, the explanation might again stem from a combination of economic sentiment and interest rate expectations, which of course have a stronger impact on buying decisions. With economic sentiment declining from the start of 2014 onwards, interest rates began to fall, but so did financing expectations as defined by ZEW and JLL (2018). Although effective rates on new mortgage loans fell below $2 \%$ for the first time in early $2015,{ }^{10}$ a continuing global economic mitigation quickly deteriorated the reimbursed financing expectations. The improvement in liquidity on the investment market from 2016 Q2 onwards might have

$\overline{10}$ Accoring to Deutsche Bundesbank (2020). 
been initiated by the ECB decision to stimulate the Eurozone economy with further expansionary measures which bolstered the economy and at the same time ensured a continuing low interest rate environment.

Liquidity development on the rental market, regarding the economic and socioeconomic factors exhibits a very similar picture. As with prices on the rental market regions assigned to liquidity cluster 1 , i.e. regions with a relatively strong liquidity development, at the median exhibit a relatively low unemployment rate of $2.6 \%$ compared to $3.58 \%$ in liquidity cluster 2 as well as a relatively high disposable household income of $€ 48.66$ thousand compared to $€ 40.54$ thousand in liquidity cluster 2 . The decline in the unemployment rate was more distinct in liquidity cluster 2 and household disposable income growth was slightly stronger in liquidity cluster 2 . The difference between liquidity cluster 1 and liquidity cluster 2 is very pronounced in terms of real GDP, with $€ 5.04$ million compared to $€ 4.37$ million. Thus, liquidity was especially increasing in extremely productive regions. These regions also experienced a relatively strong increase in real GDP of $10.12 \%$ in liquidity cluster 1 and $8.4 \%$ in liquidity cluster 2 . With regard to population, liquidity cluster 1 and liquidity cluster 2 are very similar. Working population is slightly higher in liquidity cluster 1 . The growth rates of these two variables, however, are stronger in liquidity cluster 1. While population in liquidity cluster 1 regions has been increasing by $3.22 \%$, liquidity cluster 2 regions only experienced a small plus of $0.65 \%$. Hence, again the increasing demand for space seems to be a reliable liquidity driver.

Out of the 158 regions assigned to cluster 1 by price, 123 regions are also assigned to liquidity cluster 1 and hence can be characterized as "hot" rental markets. These markets show the strongest development of population with an increase of $3.97 \%$, working population with a plus of $2.72 \%$ and real GDP with a growth of $10.9 \%$ over the observation period. These factors generate a higher demand for space, leading to tight housing markets and, thus, result in a strong upward price and liquidity development on the rental market. Furthermore, these regions are characterized by the lowest unemployment rate of $2.37 \%$, by far the highest disposable household income of $€ 50.89$ thousand and with $€ 5.04$ million real GDP is also relatively high. NUTS 3 regions assigned to the cluster combination $(2,1)$, exhibit the highest real GDP of $€ 5.1$ million, with 180.56 thousand inhabitants are the most populated and have the highest working population of 115.95 thousand people. Therefore, demand in these regions could be relatively high, resulting in a strong liquidity development. The respective growth variables that indicate the present and future development, however, are less outstanding, leading to the relatively weak price development. With an increase of $2.33 \%$ and $9.69 \%$ respectively, cluster $(1,2)$ exhibits the second largest increase in population and real GDP. Furthermore, with $35.98 \%$ cluster $(1,2)$ experienced the biggest drop in the unemployment rate. These cities seem to have a promising future and, thus, the increase in demand for space leads to a pronounced increase in rents. Liquidity, however, stays weak as these markets do not seem to be too overrun. The weakest NUTS 3 regions by means of economic and socioeconomic data are the 129 regions assigned to cluster combination $(2,2)$. They show a very low population development of $0.27 \%$ and even a loss in working population of $1.68 \%$. Moreover, with $8.21 \%, 3.66 \%$ and $€ 40.02$ thousand, cluster $(2,2)$ displays the weakest real GDP growth, the highest unemployment rate as well as the lowest disposable household 
Population (bars, left y-axis) \& growth rate (line, right y-axis)

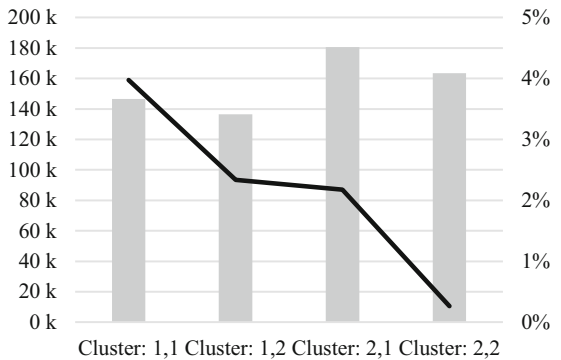

Real GDP (bars, left y-axis) \& growth rate (line, right y-axis)

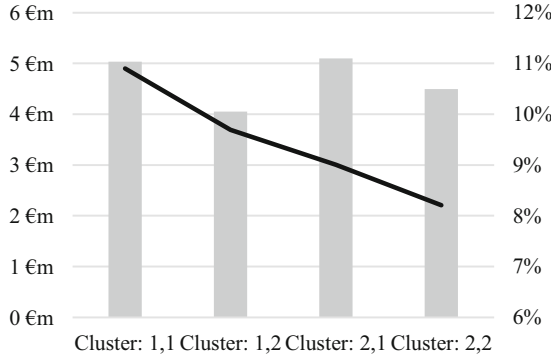

HH disposable income (bars, left y-axis) \& growth rate (line, right y-axis)

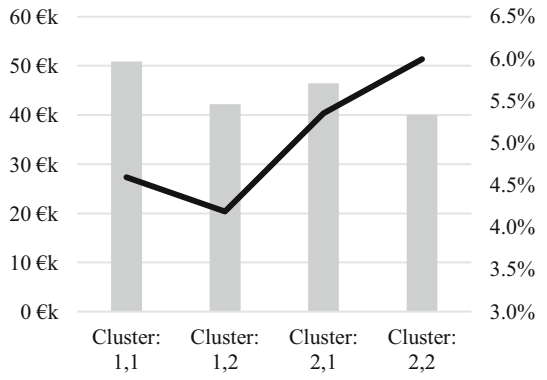

Working population (bars, left y-axis) \& growth rate (line, right y-axis)

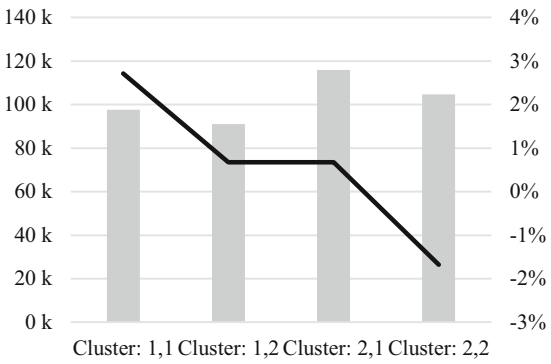

Unemployment rate (bars, left y-axis) \& growth rate (line, right y-axis)

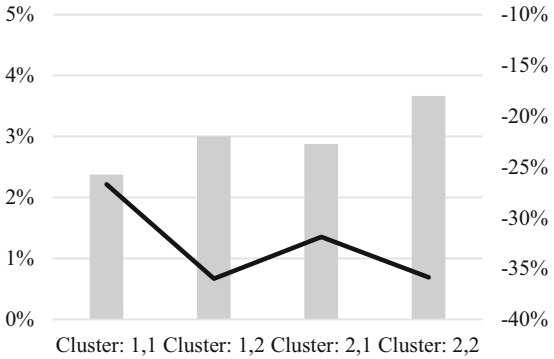

Fig. 10 Socioeconomic data by cluster affiliation, rental market. The figure displays the socioeconomic data by cluster on the rental market. The NUTS 3 regions are allocated to a specific cluster by applying the partitioning around medoids (PAM) algorithm on the price and liquidity index values, respectively. The grey bars exhibit the actual values of the respective variables, labelled on the left $y$-axis. The black lines display the respective growth rates and are labelled on the right $y$-axis. The data consists of $3,168,458$ observations on the residential rental market. The sample period is 2013 Q1-2018 Q4

income. Due to the underlying development, strong price and liquidity increases are not expected in these regions for the near future. Figure 10 summarizes the economic and socioeconomic data for the four possible cluster combinations on the rental market. 
As depicted in Fig. 11, the geographic analysis of the rental market displays a more differentiated pattern. Again, most of the strongest markets, in terms of price and liquidity development, are located in the southern part of Germany. In the northern part, however, almost exclusively the economically very strong performing regions are allocated to price and liquidity cluster 1 . Among those are for example Berlin, Bremen, Cologne, Hanover and Wolfsburg, where the Volkswagen AG has its headquarters and a large production facility.

Within the more differentiated pattern, the allocation of eastern German regions is also much more descriptive. While the share of eastern German regions allocated to price and liquidity cluster 2 for the investment market was between 60 and $70 \%$, on the rental market $83.3 \%$ of all eastern German regions in the sample are allocated to price cluster 2 and $86.1 \%$ to liquidity cluster 2 . The preference for western German regions on the rental market is emphasized by comparing the ratio of the share of eastern German regions allocated to cluster $(1,1)$ to the share of those allocated to cluster $(2,2)$. For the investment market, the ratio of the share of eastern German regions allocated to the strongest cluster in relation to the weakest cluster is $1: 2$, while on the rental market the ratio is 1:10. So the share of eastern German regions allocated to the "coldest" markets is much higher on the rental market. The same holds true for the economically underdeveloped regions of which $75.8 \%$ are allocated to price cluster 2 and $64.7 \%$ (slightly less than on the investment market) to liquidity cluster 2. While on the investment market the distribution of economically weak regions to the clusters is indifferent of the location of those regions, on the rental market $84 \%$ of the economically underdeveloped regions assigned to price cluster 1 are not in eastern Germany. For the liquidity cluster 1 it is $83 \%$.

These findings imply that on the rental market the demand for dwellings in economically weak regions is much less pronounced then on the investment market. As economically non-performing regions are not in the centre of attention of developers and landlords, we neglect increased supply in this context. This very selective demand for economically solid regions illustrates one of the largest benefits of the rental market, which is the higher flexibility tenants have in comparison to owners. For tenants it is much easier to select their place of residence or to form a decision to relocate based on fundamental data. In a polycentric country like Germany which has at the same time comparatively high ancillary acquisition costs for real estate of up to $10 \%$, a large rental market facilitates a more flexible domestic migration.

\subsection{Summary and further implications}

With its very granular analysis of 380 regions and the subsequent classification of the regions by price and the corresponding market liquidity on the residential investment and rental market, the study was able to reveal new insights to the German residential market and to draw valuable implications.

1. Over the same observation period and in the same regions, the ratio of dwellings offered for rent to those offered for investment was 2:1, demonstrating the size and importance of the rental market in Germany. 


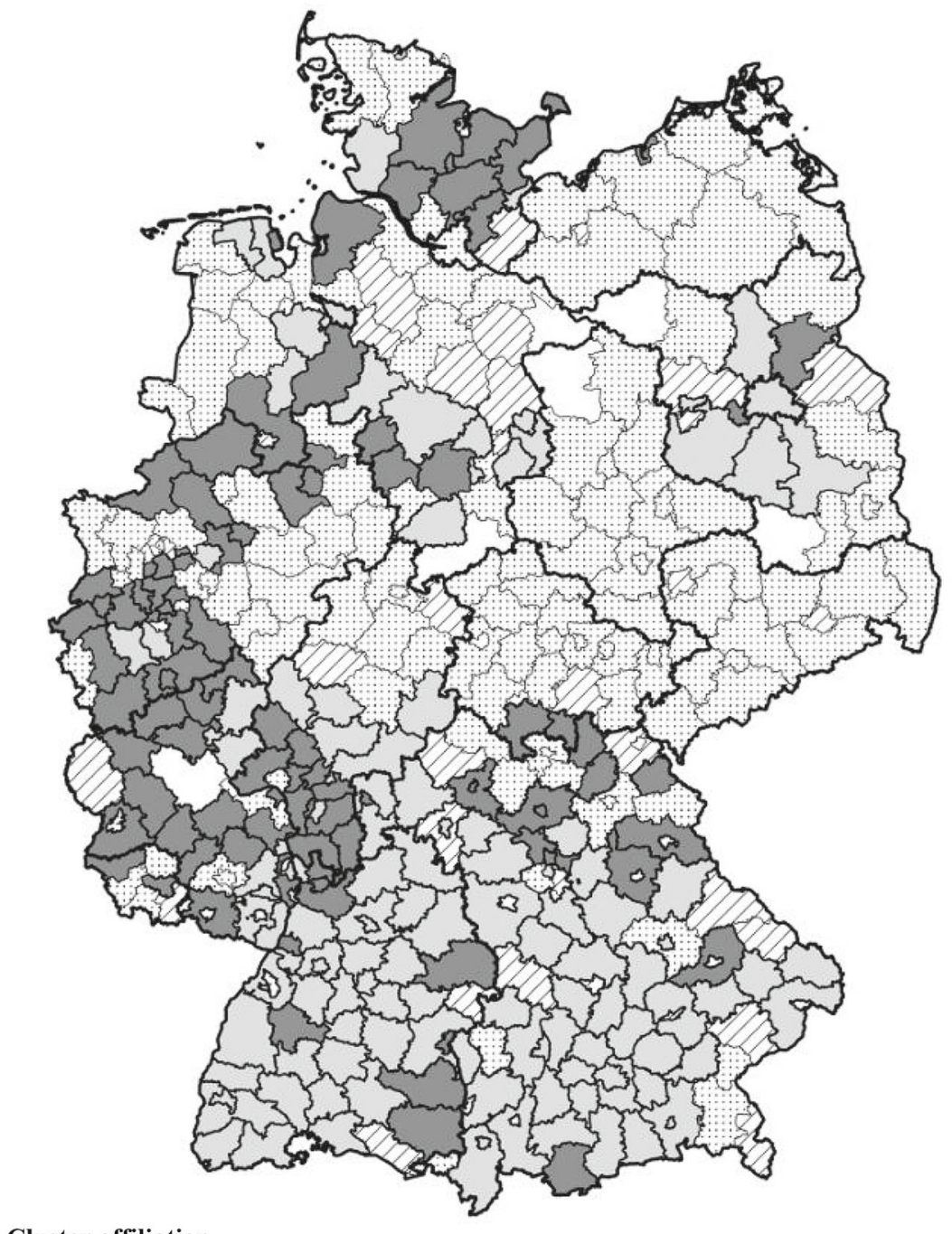

Cluster affiliation

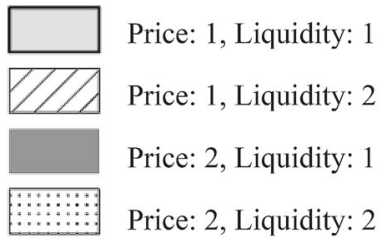

Fig. 11 Allocation of NUTS 3 regions to price and liquidity clusters, rental market. The figure displays the geographic distribution of the individual clusters. The NUTS 3 regions are allocated to a specific cluster by applying the partitioning around medoids (PAM) algorithm on the price and liquidity index values. The data consists of 3,168,458 observations on the residential rental market. The sample period is 2013 Q1-2018 Q4 
2. The optimal way to analyse commonalities and differences between the investment market and the rental market of 380 German NUTS 3 regions is by allocating the regions to two clusters based on their price and liquidity development, respectively.

3. On the investment market, the allocation to the price cluster is strongly depending on the actual values of fundamental data like population, working population and real GDP, as well as their growth rates. The allocation to liquidity clusters is much more depending on growth rates in those variables, i.e. liquidity comes with economic improvement.

4. The geographic analysis revealed that most of the regions allocated to price and liquidity cluster 1 are located in the economically strong southern half of the country. In addition, it seems that on the investment market, strong economic hubs have large spillover effects on surrounding regions.

5. On the rental market, regions allocated to price cluster 1 exhibit a relatively small size in terms of population and working population but show strong economic fundamentals like GDP, unemployment rate and disposable household income. For the liquidity clustering the size of the regions plays an important role as well.

6. The geographic analysis for the rental market reinforces these findings, as a very strong dependence on economically strong regions is revealed.

7. Regarding the four analysed categories, price and liquidity on the investment and rental market respectively, it is obvious that regions allocated to cluster 1 are characterized by relatively strong and favourable economic and socioeconomic conditions and developments in recent periods.

As stated above, the strong demand for economically prosperous regions on the rental market is not very surprising and exhibits one of the most important benefits of renting a dwelling, which is flexibility. If the quality of the flat or the chosen region does not live up to the expectations or worsened since moving in, both can be substituted within a timespan of 3 month. In addition to that, a large and functioning rental market enables people willing to move without having the financial resources to buy a home. A circumstance which is non-negligible for people moving to more prosperous economic regions.

The strong demand for economically prosperous regions on the investment market might only be obvious at first sight. The reader with a background in economics might suppose that buying a dwelling only in prosperous regions is the most natural thing to do, however, buying a home in Germany is more regarded as consumption than as an investment. Professional landlords on the other hand should of course take the fundamentals into account, when doing the market analysis before buying new dwellings. This is where another peculiarity of the German real estate market comes in. Only a small proportion of dwellings offered for rent is actually offered by profit oriented private institutions, whereas the majority is offered by non-professional individual landlords. According to the GdW (2016) approximately $37 \%$ of all dwellings are offered by non-professional landlords whereas only about $8 \%$ are offered by commercial institutions. Since the dwellings which experienced the strongest price increase seem to be chosen in a very institutional way by analysing fundamental data, a possible implication is, that the broad mass of private non-professional landlords how they are called, actually became very professional and sophisticated real estate investors. So in 
contrast to the stock market, for which German individuals are known to not be very attracted to, the residential real estate market is where they quite professionally invest their money.

While the above was the rather positive message of this article, the ongoing price increase on both the investment and the rental market further decreases the affordability of living space. This is a very topical issue in Germany, as especially in cities and metropolitan regions, large parts of the population are not able to create ownership or have to accept a monthly rent at or even above $40 \%$ of the monthly household income. Whereas this study is not able to derive specific strategies for providing affordable living space or easing tight residential markets, it might assist policy makers in detecting overheating markets and facilitate a categorization of regions according to their market tightness. Herewith, policy makers should have a better understanding of which regions they should focus on and where market interventions are most urgent. The separate clustering enables policy makers to derive regionally varying strategies based on the pricing of markets, the tightness of markets measured by liquidity, and a combination of both.

\section{Conclusion}

It is the aim of this paper to build quality- and spatial-adjusted price indices for the major German residential investment and rental markets on a regional basis and to complement each with a liquidity index, in order to obtain a very detailed assessment of the German residential real estate market. In the context of this study, liquidity is examined with a time-based measure and does not include transaction cost, volumebased, price impact or return-based measures.

While the mere analysis of descriptive statistics on the investment and rental market already indicated a trend of rising prices and declining time on market, the analysis of quality- and spatial-adjusted price indices eliminates the possibility that these trends are due to changes in the quality of the housing stock. Therefor a cluster analysis is conducted, separately for the price and liquidity development on the investment and rental market. For each of these four categories the average silhouette method suggests the optimal number of clusters to be two. The regions are then assigned to one of two clusters based on the partitioning around medoids (PAM) clustering algorithm, in order to identify common market movements and to facilitate the interpretation of the results for the 380 regions over the observation period from 2013 Q1 to 2018 Q4.

The highest price increase on the investment market is identified for dwellings within the economically strongest and largest regions, which also exhibit higher growth rates of the variables depicting the demand for space. The liquidity development is strongest in regions that are relatively small in terms of population and working population, however, have experienced the largest growth rates in the socio-economic variables. While most of the regions allocated to the clusters with the sharpest increase in price and liquidity are found in the southern half of the country, economically strong metropolitan regions in the northern part of the country seem to have a significant impact on the price and liquidity development of the surrounding regions. Those 
spillover effects are revealed for cities like Berlin, Frankfurt, Hamburg, Hanover and Rostock.

On the rental market, the dwellings which experienced the sharpest price increase are found in the economically strongest, however, relatively small regions. The allocation to the highest liquidity cluster can be found for economically very strong regions supported by relatively high population growth. The geographic analysis underlines the importance of strong economic data for significant demand on the rental market, since most eastern German regions as well as the economically underdeveloped regions are assigned to the weaker price and liquidity clusters.

To summarize, it becomes obvious that the allocation to cluster 1 for price as well as liquidity on the investment and rental market is supported by higher growth rates in the variables population, working population, and real GDP, implying higher demand for space. Furthermore, in each of the four categories cluster 1 reveals a lower unemployment rate as well as a higher disposable income. The decline in the unemployment rate as well as the increase in the disposable household income, however, is more pronounced in cluster 2 . This might stem from the relatively high or respectively low values these variables in cluster 2 come from.

One of the most interesting implications which can be drawn based on the findings of this paper is, that apparently a large part of the German population has developed into professional real estate investors. In Germany, the largest share of landlords is the one of the so-called non-professional landlords. As the regions assigned to the cluster with the most significant price increase seem to be chosen based on a very sophisticated market analysis, by identifying the regions with the strongest fundamental data, it seems like the dominating market players have significantly increased their knowledge and approach for investing in residential real estate.

A peculiarity of the analysis described in the paper is, that it is easily applicable to other residential markets. The findings of this paper are of course limited by the rather short sample period of only 6 years. Price and liquidity development before 2013 Q1 could not be incorporated because of the absence of data. Furthermore, due to a lack of transaction prices on the entire German residential real estate market asking prices operate as a "take it or leave it option" to the buyer or tenant. While this assumption seems to be plausible on the rental market, the availability of transaction prices on the investment market could further improve the knowledge of and the insights about the German residential real estate market. This topic will certainly be of major interest for future research as soon as data availability in Germany becomes less restricted. Moreover, an analysis of the intertemporal relationship between the investment and rental market, incorporating time lags, might be of further interest in order to gain deeper insights to the interdependencies of the investment and rental market. This classification could then be used to extend the price versus rent literature. The center of a city might be specified not only geographically but rather as an economic and sociodemographic city center. Furthermore, the proximity to local public transport and other amenities, tourism hotspots, commuting flows as well as the distance to adjacent urban areas might improve the insights of this analysis. The type of neighborhood, schools and noise, e.g. from a highway, should be considered as well. Including these additional spatial variables, would lead to a more precise and detailed spatial mapping 
of a city. These variables would most likely lead to a change in the impact of the current variable "distance to the NUTS 3 center".

Acknowledgements Open Access funding provided by Projekt DEAL. The authors especially thank PATRIZIA AG for contributing to this study. All statements of opinions are those of the authors and do not necessarily reflect the opinion of PATRIZIA AG or its associated companies.

Open Access This article is licensed under a Creative Commons Attribution 4.0 International License, which permits use, sharing, adaptation, distribution and reproduction in any medium or format, as long as you give appropriate credit to the original author(s) and the source, provide a link to the Creative Commons licence, and indicate if changes were made. The images or other third party material in this article are included in the article's Creative Commons licence, unless indicated otherwise in a credit line to the material. If material is not included in the article's Creative Commons licence and your intended use is not permitted by statutory regulation or exceeds the permitted use, you will need to obtain permission directly from the copyright holder. To view a copy of this licence, visit http://creativecommons.org/licenses/by/4.0/.

\section{References}

an de Meulen P, Mitze T (2014) Exploring the spatial variation in quality-adjusted rental prices and identifying hot spots in Berlin's residential property market. Region Stud Region Sci 1:310-328

Allen MT, Rutherford RC, Thomson TA (2009) Residential asking rents and time on the market. J Real Estate Financ Econ 38:351-365

Ametefe F, Devaney S, Marcato G (2011) Estimating liquidity in real estate markets. IMF Research Program, 2015

Amihud Y (2002) Illiquidity and stock returns: cross-section and time-series effects. J Financ Mark 5:31-56

Amihud Y, Mendelson H (1986) Asset pricing and the bid-ask spread. J Financ Econ 17:223-249

Bauer TK, Feuerschütte S, Kiefer M, an de Meulen P, Micheli M, Schmidt T, Wilke LH (2013) Ein hedonischer Immobilienpreisindex auf Basis von Internetdaten: 2007-2011. AStA Wirtschafts- Sozialstatistisches Arch 7:5-30

Berkovec JA, Goodman JL Jr (1996) Turnover as a measure of demand for existing homes. Real Estate Econ 24:421-440

Brounen D, Eichholtz P, Ling D (2009) The liquidity of property shares: an international comparison. J Real Estate Econ 37:413-445

Cajias M (2018) Is there room for another hedonic model? The advantages of the GAMLSS approach in real estate research. J Eur Real Estate Res 11:204-245

Cauley SD, Pavlov AD (2002) Rational delays: the case of real estate. J Real Estate Financ Econ 24:143-165

Clayton J, MacKinnon G (2000) Measuring and explaining changes in REIT liquidity: moving beyond the bid-ask spread. Real Estate Econ 28:89-115

Collett D, Lizieri C, Ward C (2003) Timing and the holding periods of institutional real estate. Real Estate Econ 31:205-222

Cox DR (1972) Regression models and life-tables. J R Stat Soc Ser B (Methodol) 34:187-220

Das S, Hanouna P (2010) Run lengths and liquidity. Ann Oper Res 176:127-152

de Haan J (2010) Hedonic price indexes: a comparison of imputation, time dummy and 're-pricing' methods. J Nat Stat 230:772-791

Demsetz H (1968) The cost of transacting. Quart J Econ 82:33-53

Deutsche Bundesbank (2020) Effektivzinssätze Banken DE/Neugeschäft/besicherte Wohnungsbaukredite an private Haushalte (Code BBK01.SUD531). Accessed 28 Mar 2020

Diewert EW (2003) Hedonic regressions: a review of some unresolved issues. In: 7th meeting of the Ottawa Group, Paris, May

Federal Ministry for Economic Affairs and Energy: Koordinierungsausschuss der Gemeinschaftsaufgabe „Verbesserung der regionalen Wirtschaftsstruktur“ (GRW) (2016) Regionalpolitischer Bericht der Bund-Länder-Gemeinschaftsaufgabe „Verbesserung der regionalen Wirtschaftsstruktur“ 2016. https://www.bmwi.de/Redaktion/DE/Publikationen/Wirtschaft/regionalpolitischer-berichtbund-laender-gemeinschaftsaufgabe-verbesserung-regionale-wirtschaftsstruktur-2016.pdf?_blob= publicationFile\&v=4. Accessed 16 Aug 2019 
Federal Statistical Office (2019a) Baufertigstellungen von Wohn- und Nichtwohngebäuden unter anderem nach Bauherren-Lange Reihen. https://www-genesis.destatis.de/genesis/online (Code 31121-0001). Accessed 17 Aug 2019

Federal Statistical Office (2019b) Preisindizes für Wohnimmobilien. https://www-genesis.destatis.de/ genesis/online (Code 61262-0001). Accessed 17 Aug 2019

Federal Statistical Office (2019c) Verbraucherpreisindex für Deutschland. https://www-genesis.destatis.de/ genesis/online (Code 61111-0003). Accessed 17 Aug 2019

Fisher J, Gatzlaff D, Geltner D, Haurin D (2003) Controlling for the impact of variable liquidity in commercial real estate price indices. Real Estate Econ 31:269-303

Fisher J, Ling D, Naranjo A (2009) Institutional capital flows and return dynamics in private commercial real estate markets. Real Estate Econ 37:85-116

Follain JR, Velz OT (1995) Incorporating the number of existing home sales into a structural model of the market for owner-occupied housing. J Hous Econ 4:93-117

GdW Bundesverband deutscher Wohnungs- und Immobilienunternehmen e.V. (2016) Anbieterstruktur auf dem deutschen Wohnungsmarkt. https:/web.gdw.de/uploads/pdf/infografiken/2016/Anbieterstruktur. pdf. Accessed 17 Aug 2019

Geltner M, Miller N, Clayton J, Eichholtz P (2014) Commercial real estate analysis and investments, 3rd edn. Ohio OnCourse Learning, Mason

Genesove D, Mayer CJ (1997) Equity and time to sale in the real estate market. Am Econ Rev 87:255-269

Glascock J, Lu-Andrews R (2013) An examination of macroeconomic effects on the liquidity of REITs. J Real Estate Financ Econ 49:23-46

Goldberger AS (1968) The interpretation and estimation of Cobb-Douglas functions. Econom J Econom Soc 36:464-472

Halvorsen R, Pollakowski HO (1981) Choice of functional form for hedonic price equations. J Urban Econ 10:37-49

Heinrich M, Just T (2016) Wie heterogen sind deutsche Städte? Zur Segmentierung deutscher Wohnimmobilienmärkte. Schriftenreihe der Universität Regensburg, Beiträge zur Immobilienwirtschaft

Held T, Waltersbacher M (2015) Wohnungsmarktprognose 2030. BBSR-Analysen KOMPAKT, Nr 7. Bundesamt für Bauwesen und Raumordnung, Bonn

Just T, Heinrich M, Wiersma S (2019) Segmentierung deutscher Wohnimmobilienmärkte, gif e.V. working paper

Kain JF, Quigley JM (1970) Measuring the value of housing quality. J Am Stat Assoc 65:532-548

Karolyi GA, Lee KH, Van Dijk MA (2012) Understanding commonality in liquidity around the world. J Financ Econ 105:82-112

Kaufman L, Rousseeuw PJ (1987) Clustering by means of medoids. In: Dodge Y (ed) Statistical data analysis based on the L1-norm and related methods. Elsevier/North-Holland, Amsterdam, pp 405-416

Kaufman L, Rousseeuw PJ (1990) Finding groups in data: an introduction to cluster analysis. Wiley, New York

Kluger BD, Miller NG (1990) Measuring residential real estate liquidity. Real Estate Econ 18:145-159

Krainer J (1999) Real estate liquidity. Econ Rev 3:14-26

Michels W, Hiller N, Oberst C (2011) Wohnungsmarktregionen in Deutschland: Abgrenzung und Struktur funktionaler Wohnungsmärkte. Institut für Siedlungs- und Wohnungswesen

Pastor L, Stambaugh RF (2003) Liquidity risk and expected stock returns. J Polit Econ 111:642-685

Rigby RA, Stasinopoulos DM (2005) Generalized additive models for location, scale and shape. J R Stat Soc Ser C (Appl Stat) 54:507-554

Sarr A, Lybek T (2002) Measuring liquidity in financial markets. IMF Working Paper No. 02/232

Shimizu C, Nishimura KG, Watanabe T (2012) House prices from magazines, realtors, and the land registry. In: Bank of International Settlements (eds) Property market and financial stability, BIS Papers No. 64, pp 29-38

Stein JC (1995) Prices and trading volume in the housing market: a model with down-payment effects. Quart J Econ 110:379-406

Syed I, Hill RJ, Melser D (2008) Flexible spatial and temporal hedonic price indexes for housing in the presence of missing data. UNSW Australian School of Business Research Paper

Triplett J (2004) Handbook on hedonic indexes and quality adjustments in price indexes: application to information technology products. STI OECD Working Papers No. 09

Voigtländer M (2009) Why is the German homeownership rate so low? Hous Stud 24:335-372 
Zentrum für Europäische Wirtschaftsforschung (ZEW) GmbH and Jones Lang LaSalle SE (2018) DIFIReport 3. Quartal 2018. https://ftp.zew.de/pub/zew-docs/DIFI/DIFI092018.pdf. Accessed 28 Mar 2019

Publisher's Note Springer Nature remains neutral with regard to jurisdictional claims in published maps and institutional affiliations.

\section{Affiliations}

\section{Marcelo Cajias $^{1}$. Philipp Freudenreich ${ }^{2}$ (D) Anna Freudenreich ${ }^{2}$. Wolfgang Schäfers ${ }^{2}$}

$\bowtie \quad$ Philipp Freudenreich

philipp.freudenreich@irebs.de

Marcelo Cajias

marcelo.cajias@patrizia.ag

Anna Freudenreich

anna.freudenreich@irebs.de

Wolfgang Schäfers

wolfgang.schaefers@irebs.de

1 Patrizia Immobilien AG, Fuggerstrasse 26, 86150 Augsburg, Germany

2 International Real Estate Business School, University of Regensburg, Universitaetsstrasse 31, 93053 Regensburg, Germany 